\title{
Meso-FE modelling of textile composites: Road map, data flow and algorithms
}

\author{
Stepan V. Lomov ${ }^{\text {a,* }}$, Dmitry S. Ivanov ${ }^{a}$, Ignaas Verpoest ${ }^{a}$, Masaru Zako ${ }^{\text {, }}$, \\ Tetsusei Kurashiki ${ }^{b}$, Hiroaki Nakai ${ }^{b}$, Satoru Hirosawa ${ }^{b}$ \\ a Department of Metallurgy and Materials Engineering, Katholieke Universiteit Leuven, Kasteelpark Arenberg 44, B-3001 Leuven, Belgium \\ ${ }^{\mathrm{b}}$ Graduate School of Engineering, Osaka University, 2-1 Yamadaoka, Suita, Osaka 565-0871, Japan
}

Received 28 June 2006; received in revised form 9 October 2006; accepted 14 October 2006

Available online 1 December 2006

\begin{abstract}
Meso-scale (unit cell of an impregnated textile reinforcement) finite element (FE) modelling of textile composites is a powerful tool for homogenisation of mechanical properties, study of stress-strain fields inside the unit cell, determination of damage initiation conditions and sites and simulation of damage development and associated deterioration of the homogenised mechanical properties of the composite. Meso-FE can be considered as a part of the micro-meso-macro multi-level modelling process, with micro-models (fibres in the matrix) providing material properties for homogenised impregnated yarns and fibrous plies, and macro-model (structural analysis) using results of meso-homogenisation. The paper discusses stages of the meso-FE analysis and proposes a succession of steps ("road map") and the corresponding algorithms for it: (1) Building a model of internal geometry of the reinforcement; (2) Transferring the geometry into a volume description ("solid" CAD-model); (3) Preparation for meshing: correction of the interpenetration of volumes of yarns in the solid model and providing space for the thin matrix layers between the yarns; (4) Meshing; (5) Assigning local material properties of the impregnated yarns and the matrix; (6) Definition of the minimum possible unit cell using symmetry of the reinforcement and assigning periodic boundary conditions; (7) Homogenisation procedure; (8) Damage initiation criteria; (9) Damage propagation modelling. The "road map" is illustrated by examples of meso-FE analysis of woven and braided composites.
\end{abstract}

(C) 2006 Elsevier Ltd. All rights reserved.

Keywords: Textile composites; Meso-modelling; Internal geometry; Micro-mechanics; Finite elements; Multi-level analysis

\section{Introduction}

Textile composites are structured, hierarchical materials, having three structural levels:

1. The macro(M)-level defines the 3D geometry of the composite part and the distribution of local reinforcement properties. The latter is connected to the former, as local parameters of the reinforcement (such as fibre volume fraction, reinforcement thickness and shear angle, hence local composite stiffness) are defined by

\footnotetext{
* Corresponding author. Tel.: +32163212 10; fax: +3216321990. E-mail address: Stepan.Lomov@mtm.kuleuven.be (S.V. Lomov).
}

the draping process during forming of the part. "Local" on the M-level means averaging (homogenisation) of the properties on the scale of one or several adjacent unit cells of the material, and corresponds to "global" on the meso-level. "Global" on the M-level means overall loading conditions of the part.

2. The meso(m)-level defines the internal structure of the reinforcement and variations of the fibre direction and the fibre volume fraction inside the yarns and the fibrous plies. The internal structure is defined by the reinforcement textile architecture and deformations applied to the reinforcement during the part forming. "Local" on m-level means averaging (homogenisation) on the scale of several fibres (representative volume element (RVE) for fibre packing inside the yarn) of properties as fibre 
direction, fibre volume fraction and stiffness of the impregnated yarn. "Global" on the m-level means "local" on the M-level.

3. The micro $(\mu)$-level defines the arrangement of the fibres in the RVE of the impregnated yarn or fibrous ply. "Local" data on $\mu$-level are properties of fibres, matrix and their interface. Homogenised, "global" parameters are used as "local" data on the m-level.

This paper deals with meso-level analysis of mechanical behaviour of textile composites, i.e. textile reinforcement impregnated by a solid matrix. Whilst similar issues could be considered for FE modelling of deformations of permeability of dry textile, these topics are out of scope of the present paper.

The multi-level description of composites is a well-established approach to calculation of mechanical properties [1]. The key step in the multi-level calculations is the mesolevel. For cross-ply laminates it leads to analytical solutions of the Classical Laminate Theory; for textile composites with complex internal architecture more elaborate numerical solutions are needed. The level of complexity of the description of the internal architecture starts from simple equivalent laminate or mosaic models [2-4]; the latter are elaborated into complex models, which map the geometric description of the textile meso-structure into a 3D grid of elements ("cells") [5-16]. Another approach to the approximate homogenisation of elastic properties on meso-level exploits averaging of properties of differently oriented impregnated yarns in the reinforcement, based on expressions for transformation of the stiffness tensor with the reference coordinate system [1]. This approach allows calculations for complex 3D braided, woven and knitted composites [17-28]; the inclusion-based model [29-31] could be considered as generalisation of the orientation approach.

All the approaches mentioned above are in one or another sense approximate in their representation of the reinforcement geometry and details of the stress-strain state on the meso-level. In the present paper we concentrate on the meso-modelling aiming at the maximum detalisation both of the reinforcement geometry and the stress-strain state: finite element (FE) modelling of textile composites on the meso-level (meso-FE). The main features of mesoFE are: (1) meshing of a realistic geometrical model of the reinforcement internal geometry, which represents actual volumes of the yarns, (2) application of $\mu$-homogenisation to calculate local (per finite element) properties of the impregnated yarns, accounting for local fibre volume fraction and orientation and (3) definition of boundary conditions, representing the periodic nature of the reinforcement. FE analysis of the resulting boundary value problem results in definition of the stress-strain fields on the meso-level, which allow further analysis of damage initiation and development.

The topic of meso-FE modelling has attracted much of attention in recent years. The number of publica- tions is increasing from year to year, as well as the number of groups world-wide, undertaking meso-FE modelling. The published works can be grouped as follows:

- Investigations of proper boundary conditions [32-36]: Meso-FE analysis considers a textile composite, the unit cell of which has translational symmetry in two directions, orthogonal or not (sheared reinforcement; braided fabrics). Boundary conditions (BC) applied in the meso-FE problem should correctly represent this symmetry together with the homogenised applied strains. Moreover, the unit cell may have internal symmetry, which allows reducing the size of meso-FE problem, considering $1 / 2,1 / 4,1 / 8$ or even $1 / 16$ part of the unit cell. The referenced work, especially of Whitcomb and co-workers, established a generic approach to formulation of BC, accounting for different symmetry of the unit cell.

- Meso-FE modelling of textile composites in the elastic deformation regime and with damage [32-35,37-74]: This vast pool of research provides numerous examples of modelling of primarily woven composites, with several forays into more complex 3D woven and braided structures. As far as elastic calculation of homogenised properties is concerned, the meso-FE calculations are proved to be reliable, provided that the correct geometry of yarns is used and successfully meshed. This enables one to investigate more intricate effects, such as, for example, the effect of nesting in fabric laminates $[41,50,66,75]$. Some attention has been given to the dependency of the meso-FE solution on the mesh finesse and on the order of the elements used [71]. The success of elastic homogenisation gives hope that meso-FE analysis will also provide correct local stress-strain concentrations, as evidenced by comparison with full-field measurements [44], hence allowing correct identification of onset of damage. When the geometrical features of the reinforcement are well represented in the model, the onset of damage is indeed modelled correctly $[62,64,76]$. The progression of damage presents more difficulties, and the discussion involves such issues as nonlocal criteria and energy-based damage propagation algorithms.

- Multi-scale modelling [7,10,77-83]: The general principles of hierarchical analysis of textile composites structures [1] are applied to (1) analysis of 3D-shaped textile composite parts in the elastic regime, with local stiffness of the composite, reinforced with locally deformed fabric, transferred to the macro-level for stiffness analysis of the part and (2) analysis of local damage on meso-level using loading conditions acquired in the macro-analysis of the part.

- Geometrical modelling and meshing of the unit cell structure of textile fabrics, intended for problems, different from micro-mechanical analysis (deformations and permeability of dry fabrics) [39,42,84-93]. 
On the one hand, these efforts have created valuable experience of handling the complex problem of meso-FE modelling of textiles and textile composites. On the other hand, the systematic approach, which would integrate all the stages in meso-FE analysis, and establish universally used techniques and software tools, still has to be created. The aim of the present paper is to put forward a proposal for such a "road map", based on the authors' experience in handling different stages of meso-FE, applied to different textile reinforcement architectures [32,44,45,56,65,66,69,76,83,94-98], as well as on the work of other researchers, cited above. The main issues, which will be addressed are:

- Software tools for geometric modelling of the internal structure of textile reinforcements and data transfer from such a tool to FE code. The tool which is used by the authors and which is described here, is the WiseTex software package $[83,99]$.

- "Post-processing" (in relation to the geometrical modelling) or "pre-processing" (in relation to FE analysis) of the geometrical model with the aim of eliminating inconsistencies preventing FE meshing and ensuring effective meshing. This involves solving intermediate FE problems, calculating shapes of the yarns resulting from their contact compression [65].

- Assigning local stiffness properties using information on fibre directions and volume fractions, provided by the geometrical model.

- Symmetry of the unit cell, minimisation of the problem size and boundary conditions reflecting the symmetry, including translational symmetry, representing periodicity of the unit cell $[32,34,100]$.

- Homogenisation $[56,100]$ of the composite stiffness.

- Damage initiation criteria and damage development algorithm [76].

This paper discusses these issues, using two general-purpose FE packages: the commercial ANSYS software and a package SACOM, developed by M. Zako in Osaka University in the 90s [76,101-103] and extensively used by the Osaka group of the present authors for a wide spectrum of research topics. The general discussion is illustrated by an example of meso-FE analysis of three-axial braided composite, parameters of which are shown in Table 1.

\section{Stages of meso-FE modelling}

Consider a typical problem of meso-FE modelling of a unit cell of textile composite under loading conditions representing its actual loading in a composite part. The following tasks can be performed (Fig. 1a):

- For the given applied loading (which may include also thermal and cure stresses) calculate the stress-strain fields inside the unit cell.
Table 1

Parameters of the three-axial braided composite

\begin{tabular}{lll}
\hline Parameter & Value \\
\hline Braiding pattern & & \\
& &
\end{tabular}

Areal density $\left(\mathrm{g} / \mathrm{m}^{2}\right) \quad 600$

Braiding angle $\left({ }^{\circ}\right) \quad 90$

Unit cell size (square shape) $\quad 14.4$

$(\mathrm{mm})$

Tows

Fibre diameter $(\mu \mathrm{m})$

Matrix

Fibre volume fraction in the

composite

\section{Carbon HTS 5631 Tenax 24K}

7

Epicote 828 LV/Epicure DX 5614

44

- Assess stress-strain concentrations and identify damage sites.

- When damage occurs, recalculate the local mechanical properties of the impregnated yarns and matrix and recalculate the homogenised properties of the damaged com-

a
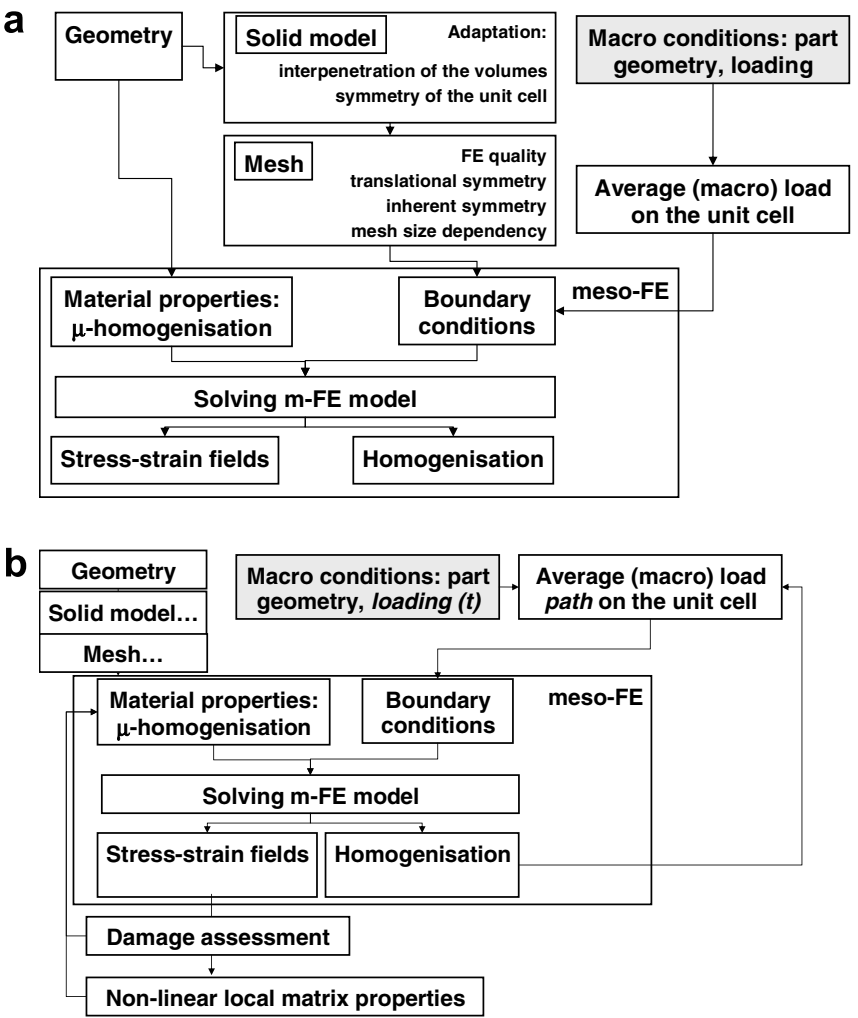

Fig. 1. "Road Maps" for meso-FE: (a) linear and (b) with damage. 
posite. These calculations may proceed for increasing loading (along a certain loading path) to calculate the non-linear behaviour of the damaged composite (Fig. 1b).

- Calculate the homogenised properties of the composite material in undamaged or damaged state.

The output of this meso-FE modeling may be:

- Details of the stress-strain fields in the unit cell.

- Influence of details of the textile architecture on mesoscale: voids, uneven distribution of fibres inside yarns/ plies, non-ideal local geometry of compacted yarns, etc.

- Stress-strain concentrations, hence strain limits for damage initiation.

- Damage development on meso-scale and deterioration of the homogenised mechanical properties.

- Material models (homogenised) to be used in macro-calculations for the elastic regime and for the non-linear behaviour of the composite, for undeformed and deformed (compression, shear, biaxial tension) state.

In the following sections the stages of the "road map" are discussed in an orderly fashion.

\section{Transforming geometrical model into description of volumes}

The geometrical and mechanical model of textiles, implemented in the software package WiseTex, provides a full description of the internal geometry of the following types of fabrics: 2D and 3D woven, two- and three-axial braided, knitted, multi-axial multi-ply stitched (non-crimp fabric). Input data include: (1) Yarn properties: geometry of the cross-section, compression, bending, frictional and tensile behaviour, fibrous content; (2) Yarn interlacing pattern; (3) Yarn spacing within the fabric repeat. Energy minimisation and approximations of the shape of the yarns using "anchor points" is employed to calculate the internal structure of the fabric in the relaxed state $[83,99,104,105]$ and under compression, bi- and uniaxial tension and shear. The fabric model is comprised of yarns and (for non-crimp fabrics) of fibrous plies.

They are transformed into volumes for FE modelling as follows.

\subsection{Yarns}

Fig. 2a illustrates the description of the yarns. The midline of a yarn is given by the spatial positions of the centres of the yarn cross-sections $\mathrm{O}: \boldsymbol{r}(s)$, where $s$ is coordinate along the midline, $\boldsymbol{r}$ is the radius-vector of the point $\mathrm{O}$. Let $\boldsymbol{t}(s)$ be the tangent to the midline at the point $\mathrm{O}$. The cross-section of the yarn, normal to $\boldsymbol{t}$, is defined by its dimensions $d_{1}(s)$ and $d_{2}(s)$ along axis $\boldsymbol{a}_{1}(s)$ and $\boldsymbol{a}_{2}(s)$. These axes are "glued" with the cross-section and rotate around $\boldsymbol{t}(s)$, if the yarn is twisted along its path (such a twist can be the result of the fabric shearing [106]). Because of this rotation the system $\left[\boldsymbol{a}_{1} \boldsymbol{a}_{2} \boldsymbol{t}\right]$ may differ from the natural coordinate system along the spatial path $[\boldsymbol{n b t}]$.

The shape of the cross-section can be assumed elliptical, lenticular, etc. Definition of the spatial positions of a yarn with a given cross-section shape in a unit cell consists therefore of five periodic functions: $\boldsymbol{r}(s)$ (then $[\boldsymbol{n b t}]$ vectors can be calculated), $\boldsymbol{a}_{1}(s), \boldsymbol{a}_{2}(s), d_{1}(s), d_{2}(s)$. These functions are calculated for all the yarns in the unit cell by the geometrical model. When used in numerical calculations, all these functions are given as arrays of values for a set of points along the yarn midline, the quality of representation of the continuous yarn lines and especially the continuity of the tangent regulated by the fineness of the divisions of the yarn middle lines.

This description fully defines the volumes of the yarns in a unit cell (Fig. 2b). The format is the same for orthogonal and non-orthogonal (angle $\alpha$, Fig. 2a) unit cells. The inplane dimensions of the unit cell $X, Y$ are given by the repeat size of the textile structure, whereas the thickness $Z$ is calculated as the difference between the maximum and minimum $z$-coordinates of the cross-sections of all the yarns in the unit cell.

To describe the fibrous structure of the unit cell, consider a point $P$ and fibrous assembly in the vicinity of this point (Fig. 2c). The fibrous assembly can be characterised by physical and mechanical parameters of the fibres near the point (which are not necessarily the same in all points of the fabric), fibre volume fraction $V_{\mathrm{f}}$ and direction $\boldsymbol{f}$ of them. If the point does not lie inside a yarn, then $V_{\mathrm{f}}=0$ and $f$ is not defined. For a point inside a yarn, the fibrous properties are easily calculated, providing that the fibrous structure of the yarns in the virgin state and its dependency of local compression, bending and twisting of the yarn are given.

The distribution of fibres over a cross-section is usually assumed uniform, and value of $V_{\mathrm{f}}$ is the same in all the points on the cross-section (but may differ from cross-section to cross-section according to the change of $d_{1}$ and $d_{2}$ ). Non-uniform distribution may be important for damage analysis $[65,98,107]$ - in this case $V_{\mathrm{f}}$ will vary over the cross-section.

\subsection{Fibrous plies in the presence of stitching}

The description of the geometry of multi-axial multi-ply stitched preforms (also called "non-crimp fabrics", NCF) includes the geometry of the stitching yarns and geometry of the fibrous plies [108]. The same approach can be used for description of structural stitching.

The stitching, even thin, interacts with the fibrous plies, which are unidirectional arrays of fibres with approximately constant thickness. The stitching causes deviations of the fibres in a ply from their uniform directions. These deviations produce fibre-free zones near stitching locations, which are regularly spaced over the ply. The local fibre volume fraction in the rest of the ply is hence increased. The fibre-free zones can be local (and called "openings" below), 
a

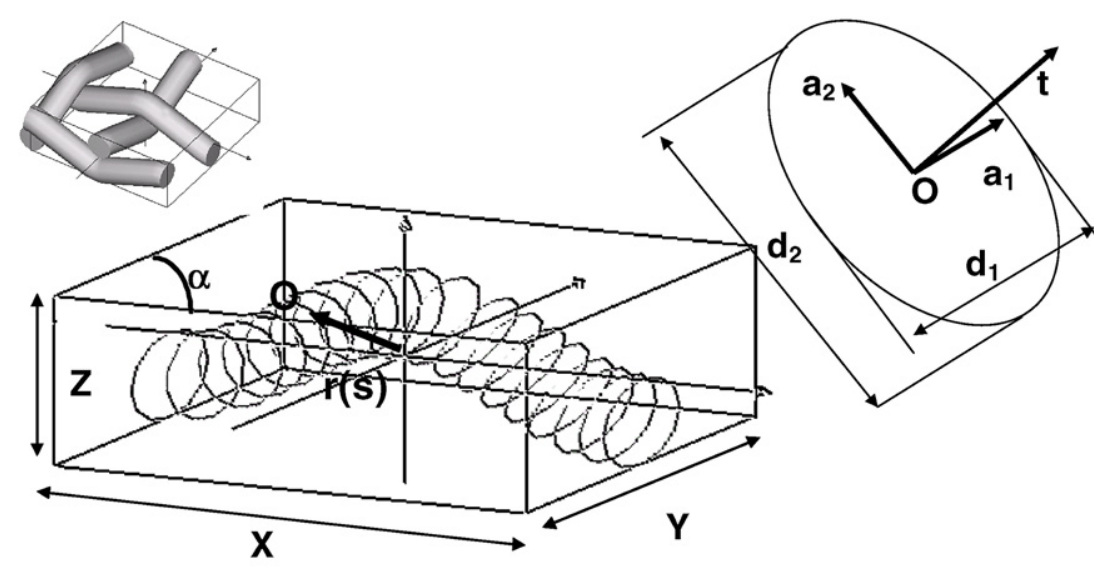

b

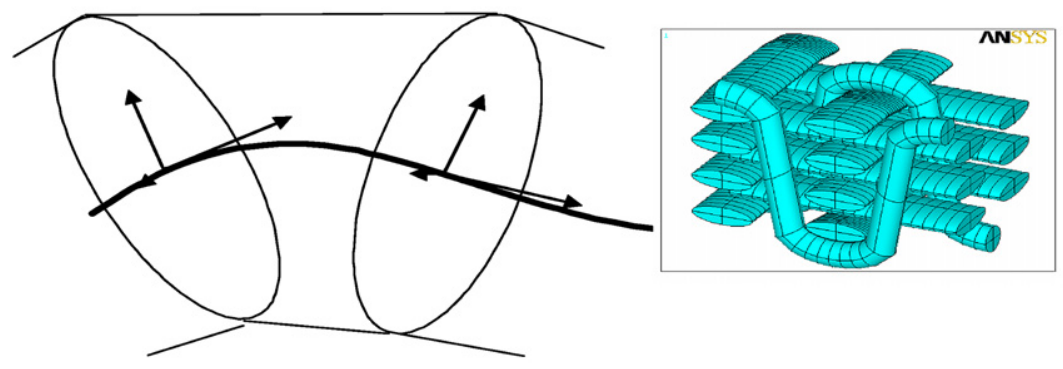

C

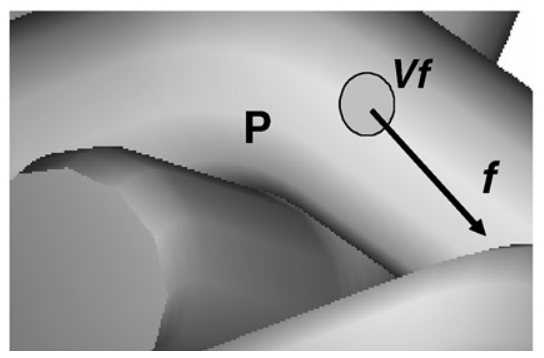

Fig. 2. Geometrical model of yarns and transformation into volumes of the solid model: (a) Cross-sections of a yarn in WiseTex model; (b) building of the solid volumes and example of the solid model subdivided into volumes; and (c) properties of the fibrous assembly at a point $P$ inside a unit cell.

or can form continuous channels in the ply (Fig. 3a and b). The width and length of the "openings" and "channels" should be measured or calculated with empirical formulae based on dimensions of the stitching yarn $[108,109]$. When sheared, the fibre density in the plies increases, and the width of the "openings" and "channels" decreases and is described by empirical formulae [109].

The complex geometry of a fibrous ply with "openings" and "channels" is represented in the geometrical model as a set of "slabs" - volumes formed by two parallel polygons (Fig. 3d). Combination of all the slabs belonging to a ply gives the ply volume, which will be used for building the mesh in the meso-FE analysis.

To describe the fibrous structure of the unit cell, consider again a point $P$ and fibrous assembly in the vicinity of this point, characterised by fibre volume fraction $V_{\mathrm{f}}$ and direction $\boldsymbol{f}$ of the fibres (Fig. 3e). Searching all the slab volumes, it is easy to determine whether the point $P$ belongs to one of the plies. If not, then $V_{\mathrm{f}}=0$ and $\boldsymbol{f}$ is not defined. If the point lies inside one of the slabs, then parameters $V_{\mathrm{f}}$ and $\boldsymbol{f}$ are defined by the properties of the corresponding ply.

In the simplest case, the fibre volume fraction is assumed to be constant inside a ply and calculated using the ply thickness, areal density of the ply, fibre density and part of the ply volume occupied by openings and channels (see [108] for details). There exists experimental evidence that in the case of structural stitching (hence thicker stitching yarns) $V_{\mathrm{f}}$ can have local variations [110]; in this case $V_{\mathrm{f}}$ will vary inside the ply volume. For plies with straight channels formed by the stitching, the assumption of uniform fibre direction is valid. An opening changes the direction of the fibres, which could be accounted for by definition of deviation of the fibre direction in the vicinity of the opening [111]. It is possible to account for random misalignment of the fibres, introducing random choice of the fibre direction within a certain interval of fibre angles. 
a

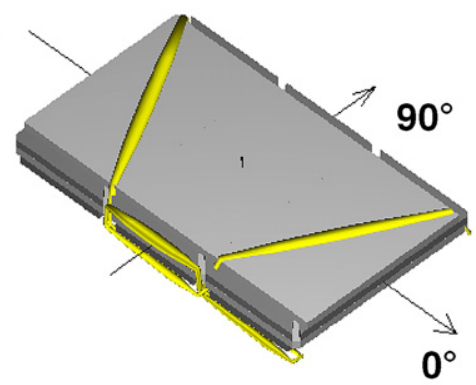

b

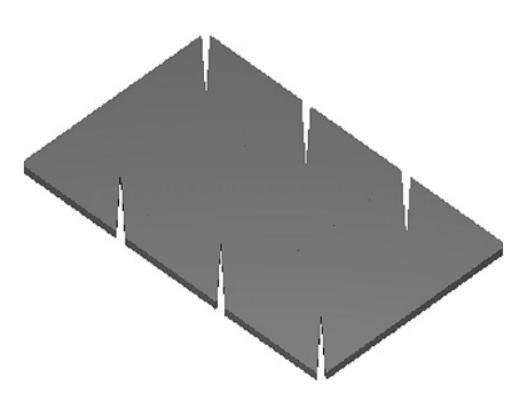

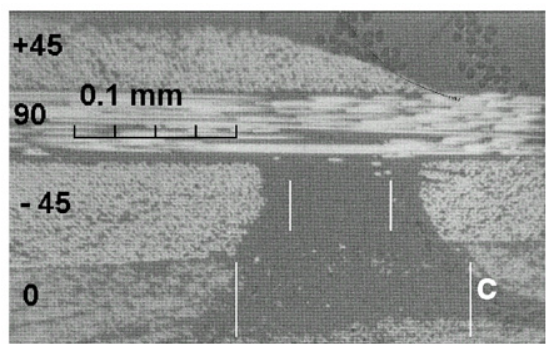

d

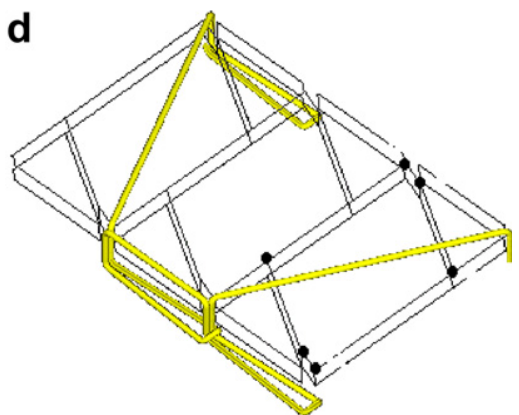

e

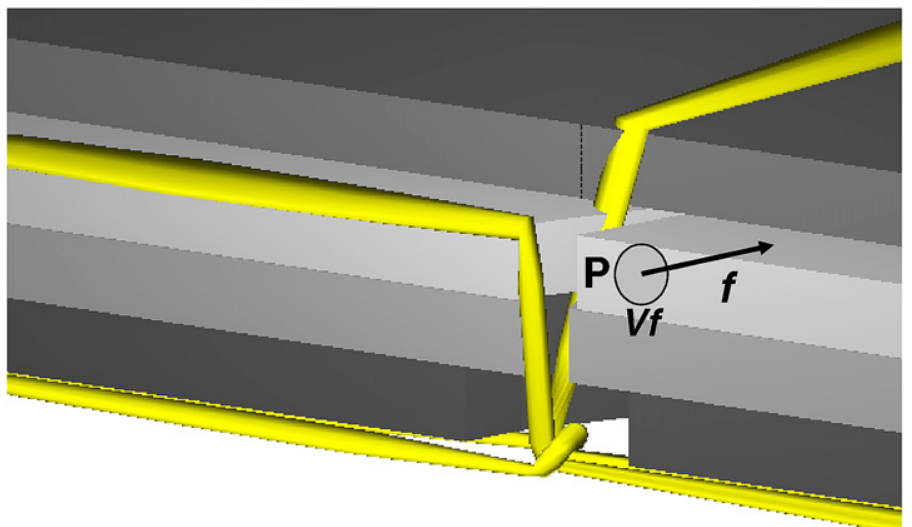

Fig. 3. Quadriaxial NCF, orientation of the fibres in the plies $0^{\circ} /-45^{\circ} / 90^{\circ} / 45^{\circ}$. (a) Full geometrical model with stitching. Note a "channel" in the first $0^{\circ}$ ply, going through the stitching sites; (b) "openings" in the $-45^{\circ} \mathrm{ply}$; (c) channels/cracks width in cross-sections of the composite plate, thick white lines show width of the cracks as computed by the model, section in the cross-direction, channel in the $0^{\circ}$ face ply and a crack in the $-45^{\circ}$ inner ply; (d) slab representation of a ply with $-45^{\circ}$ "cracks". ABCDEF - vertices of the upper polygon of one of the slabs; and (e) properties of the fibrous assembly at a point $P$ inside a unit cell.

\section{Adaptation of the solid model and meshing}

\subsection{Symmetry and boundaries of the unit cell}

Geometrical models of a unit cell can have correct translational symmetry properties, but may not be confined into a volume with flat facets (which will eventually be filled with matrix in FE model), which allows easy definition of loading and boundary conditions. To achieve that, the easiest way is to make a geometrical model of four unit cells, transform it into a solid model, and then, using tools of FE or CAD software, perform division operations. Fig. 4 illustrates this process, using an example of three-axial braided reinforcement. The model in the middle of Fig. $4 \mathrm{~d}$ produces the same fabric geometry when translated periodically in two directions, as the initial model (Fig. 4a), but it is confined into a parallelepiped. This transformation is standard for any periodic textile structure. The procedure of cutting out a repetitive element with flat facets may be especially useful in building models of layered randomly nested structures, as the geometrical models of the nested laminates and software are readily available [112].

Using the inherent symmetry of a particular fabric, it is possible to reduce the size of the model. Consider the threeaxial reinforcement shown in Fig. 4. 1/4 of the unit cell 1 is transformed into other three quarters 2,3,4 with the following mapping:

$1 \rightarrow 2\left(\right.$ rotation around the line $\left.x_{1}=x_{2}\right):$

$$
\left(x_{1}, x_{2}, x_{3}\right) \rightarrow\left(x_{2}, x_{1},-x_{3}\right),
$$

$1 \rightarrow 3$ (rotation around the axis $\left.x_{3}\right)$ :

$$
\left(x_{1}, x_{2}, x_{3}\right) \rightarrow\left(-x_{1},-x_{2}, x_{3}\right),
$$

$1 \rightarrow 4$ (rotation around the line $\left.x_{1}=-x_{2}\right)$ :

$$
\left(x_{1}, x_{2}, x_{3}\right) \rightarrow\left(-x_{2},-x_{1},-x_{3}\right) \text {. }
$$



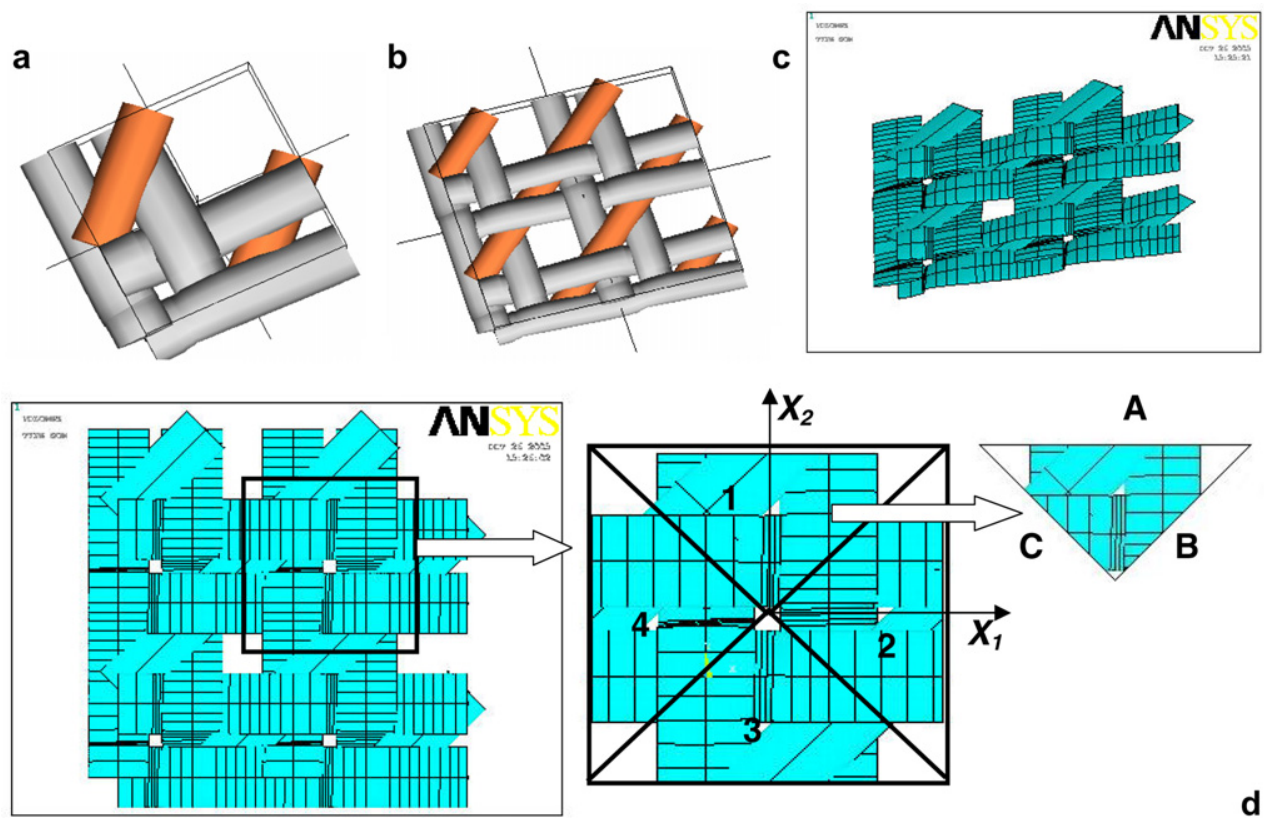

Fig. 4. Example of transformation of a solid model: three-axial braid. (a) Unit cell (WiseTex model); (b) four unit cells (WiseTex); (c) solid model of four unit cells in ANSYS; and (d) selection of one unit cell confined into a parallelepiped and minimal unit cell.

Stress-strain fields calculated for $1 / 4$ of the unit cell is mapped over the full unit cell using Eqs. (1)-(3). The symmetry equations are used to derive periodic boundary conditions for the reduced unit cell (Section 5 below). We will see that using the symmetry of the unit cell may not be possible if the loading conditions do not possess the same symmetry.

\subsection{Correcting interpenetrations of the yarn volumes}

If the geometry for the meso-FE model is acquired by direct measurement of the yarn shapes in the composite, as it is done, for example, in [48], then there are no defects in mutual placement of the yarn volumes. However, such approach has limited predictive capabilities. General-purpose geometrical models, like the models, discussed here, use several simplifying assumptions. One of these assumptions is a fixed shape (but maybe changing dimensions) of the yarns cross-sections. The shape of the yarn middle line prescribes the positions of the centres of the cross-sections. The model calculates dimensions of the cross-sections $\left(d_{1}\right.$ and $d_{2}$, see Fig. 2b), ensuring that the distance between the contacting yarn centre lines is equal to the sum of their dimensions.

For quite a wide class of woven fabrics such a treatment is sufficient to create geometrical model, which can be easily meshed in FE package. The majority of the research cited in the introduction uses such a geometry for the simple cases of not-so-tight, orthogonal 2D woven fabrics with the cross-section of the yarns either close to cylindrical or elliptical/lenticular with width-to-thickness ratio below 510. However, the condition of point or line contact does not guarantee that the surfaces of the contacting yarn never penetrate one another, and interpenetration may occur (Fig. 5). Three types of interpenetration could be identified:

1. Tight orthogonal structures with flat yarns. The interpenetrations occur close to the middle of the yarn width (Fig. 5b). This is the easiest case, which could be for some configurations mended using a lenticular cross-section shape or by modification of the yarn dimensions, preserving the cross-section symmetry (WiseTex tries to do this automatically, using compressibility of the yarn in lateral direction; a similar algorithm is proposed in [113]).

2. Non-orthogonal intersections of flat yarns (Fig. 5c). Yarn edges "cut into" the intersecting yarn. This type of interaction between yarns produces local compression, which leads to non-symmetrical yarn shapes, and cannot be resolved preserving the assumption of the shape symmetry.

3. Tight placement of the yarns, especially in $3 D$ fabrics (Fig. 5d). In reality the $Z$-yarn in this figure will be compressed laterally inside the fabric. This may not be accounted for by geometrical models. Whilst still usable for fibre orientation-, inclusion- or voxel-based models of micro-mechanics, such defects in the geometrical description are not likely to be corrected by any intersection algorithm. Meso-FE analysis in this case requires more precise geometry as a starting point.

The problem of interpenetration is not caused by assumptions of a particular model, but is a generic consequence of the constant shape of the yarns and limited point or line - control of the contacts. Attempts to cope with the problem using local reduction of the dimensions 
a
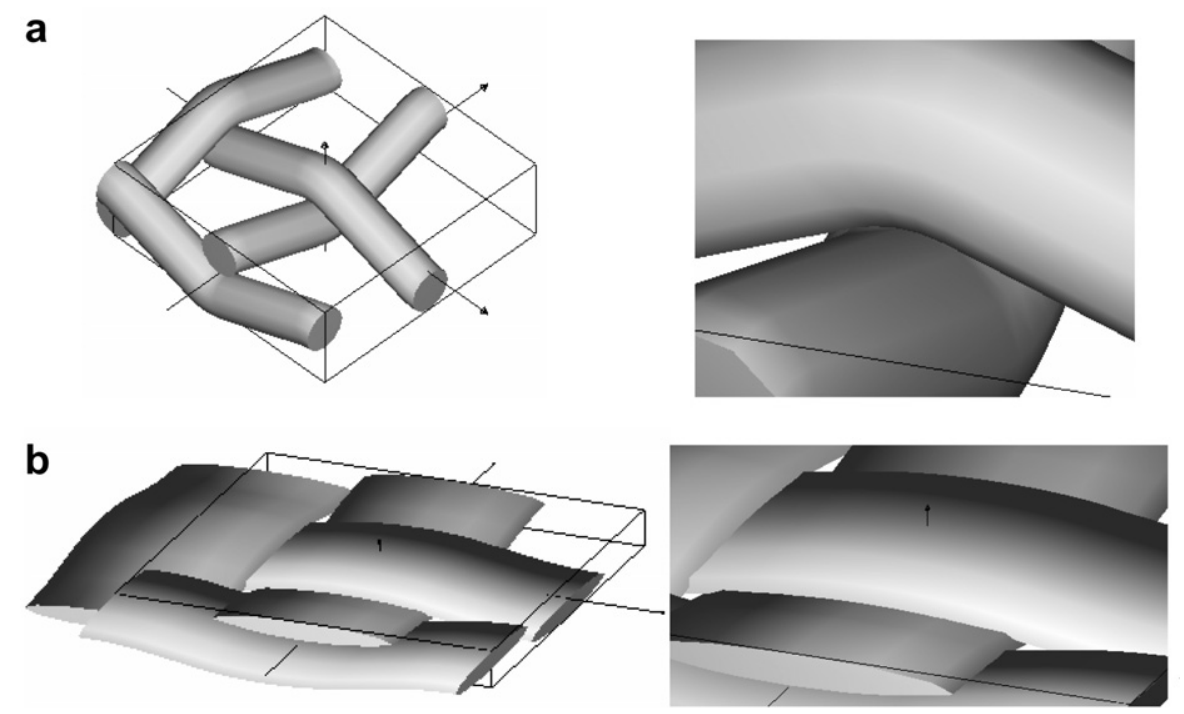

C

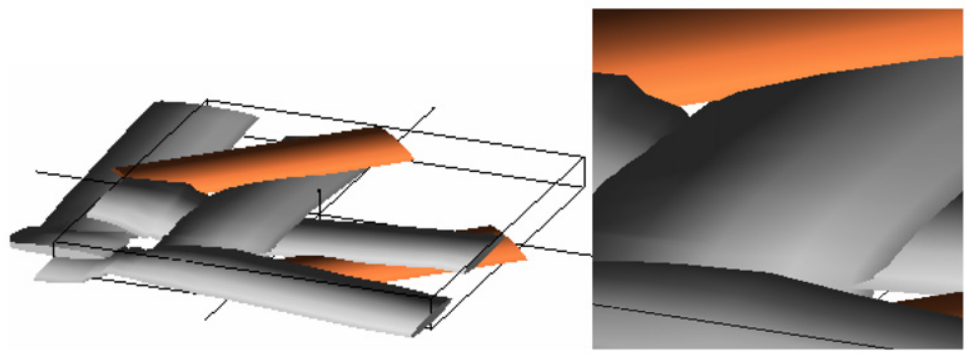

d
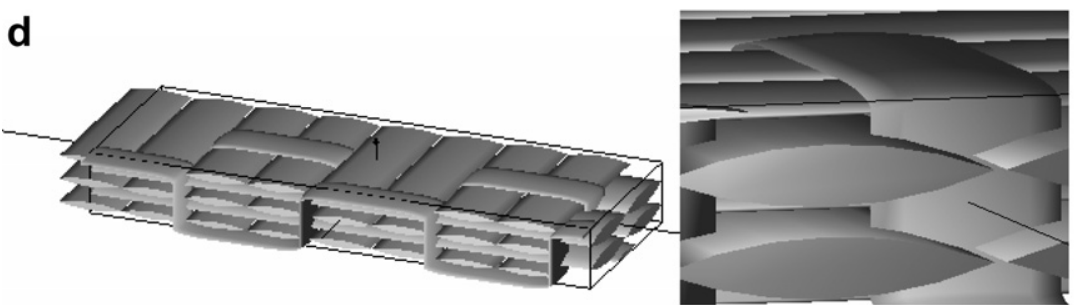

Fig. 5. Types of interpenetration of yarn volumes: (a) no interpenetration for the case of round yarns; (b) flat yarns; (c) non-orthogonal configuration; and (d) very dense $3 \mathrm{D}$ woven fabric.

of the yarns without changing the shape can solve the problem only partially, for not-so-thin cross-sections, not-sotight fabrics and only for orthogonal intersections. The more complex approach of Hivet et al. [87] with non-symmetrical shapes of the cross-sections, controlled by the shape of the intersecting yarn, is very promising, but it is implemented so far for orthogonal intersections only and is demonstrated to be working only for rather thick cross-sections (width-to-thickness ratio below 10). The ultimate geometrical model handling the problem of volume intersections is still to be developed. This model would create yarn geometries with local deflection of cross-section shape accounting for local interactions of the yarns and accommodating accordingly the shape - non-symmetrical, freely defined by the points on the contour. The straightforward, but cumbersome way of building such a model is calculating yarn contact interactions with FE simulations of dry fabric, solving contact problems, and implementing correct mechanical behaviour in tension, compression and shear of the yarns as fibrous assemblies. Existing FE models of dry fabrics $[85,86,114]$ do not deal with such models. They calculate deformations of dry fabric, starting from a certain relaxed configuration, where the interpenetration should be avoided beforehand.

The approach which we propose in the present paper, exploits the idea of calculation of local compressive deformation of the yarns (in earlier works of Zako et al. $[66,69,76,97]$ this idea was used to produce a plain woven geometry from straight yarns), but it uses this as an intermediate calculation, performed on isolated parts of the yarns, does not use contact formulation, should be in general considered as an ad hoc solution and is very far from full FE analysis of the relaxed state of dry fabrics. Nevertheless, it works effectively in quite complex cases, can handle very thin cross-section shapes (width-to-thickness about 100) and is automated for a wide class of woven rein- 
forcements, both orthogonal and non-orthogonal. The proposed algorithm creates geometries of the contacting yarns reasonably resembling the actual distortions of the regular shapes due to the contact forces. However, the rigorous comparison with the real shapes of the yarns has not yet been made (the work is on-going).

The correction of the yarn volumes for a woven fabric proceeds as follows (Fig. 6).

Step 1. Preliminary meshing and division of the unit cell (Fig. 6a). The volumes of each of the yarns, exported from the geometrical model, are meshed separately. The unit cell is subdivided in a set of sub-problems, each containing one zone of the yarn contact. The division operation is crucial for the method, as it relies on having not more then one contact zone per sub-problem. The separation is done automatically, using information of the yarn spacing and dimensions defined by the geometrical model: separation plane is positioned in the middle of the pore between the yarns.

Step 2. Analysis of interpenetrations (Fig. 6b). Consider a sub-problem. One of the contacting yarns $(A$, Fig. 6a) will be moved during the solution, another $(B)$ will remain in place. For all the points in the upper boundary of the
$A$-yarn mesh, which are situated inside another yarn, a closest boundary mesh point of the $B$-yarn is found, and the vertical distance $h$ between them is stored. The two nodes of $\mathrm{A}$ and $\mathrm{B}$ mesh form a pair $\left(P_{A}, P_{B}\right)$.

Step 3. Separation and adding beam elements (Fig. 6c). Based on the calculated $h_{p}$, where $p$ is the number of the point, and on the user-defined clearance $c$ between the two yarn volumes (Fig. 6e), the separation distance is defined as

$\Delta z=\max _{p} h_{p}+c$.

The volume $A$ is moved up by $\Delta z$. Beam elements, connecting points in the pairs $\left(P_{A}, P_{B}\right)_{p}$, are inserted.

Step 4. Solution of the intermediate FE problem (Fig. 6d). Now the volumes $A$ and $B$ will be pressed together to create a non-penetrating configuration. The displacements on the cut-out facets of the volume $\mathrm{A}$ are assigned as $u=(0,0, \Delta z)$, the cut-out facets of the volume B remain in place: $u=(0,0,0)$. The stiffness of the beam elements is given by

$E=\left\{\begin{array}{l}0, \quad l>c \\ E_{b}, \quad l \leqslant c,\end{array}\right.$
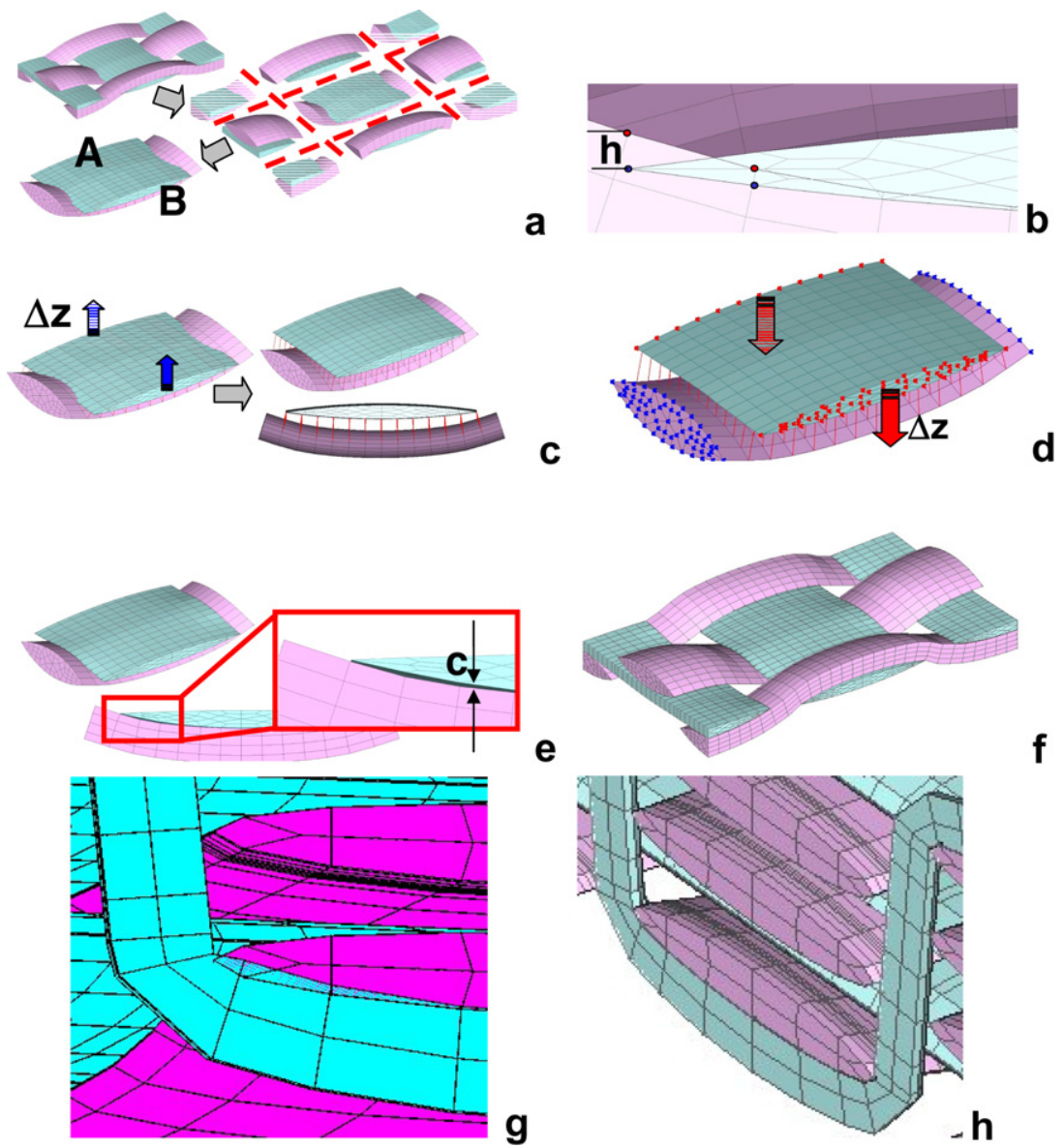

Fig. 6. Algorithm of automated correction of the yarn shapes (MeshTex): (a) subdivision of the unit cell; (b) penetrating yarn volumes; (c) separation of the yarn volumes and adding beam elements; (d) intermediate FE problem; (e) resulting non-penetrating mesh; (f) assembled model with non-penetrating yarns; (g) interpenetration of volumes of weft and $Z$-yarn in a 3D woven fabric; and (h) the corrected mesh. 
where $l$ is the length of the beam, $c$ is the user-defined clearance. The value of $E_{b}$ is arbitrary, as well as the properties assigned to the yarn volumes; the ratio of stiffness of the yarns and $E_{b}$ can be used to tune the result of the sub-modelling. The Poisson ratio for the yarn volumes is set equal to 0.5 (or just below 0.5 to avoid numerical difficulties), to preserve the yarn volume and hence the fibre volume fraction within the yarns.

The result of solving of the intermediate problem is shown in Fig. 6e. The yarn volumes are clearly separated by the clearance $c$, and the interpenetration is gone.

Step 5. Assembling the model (Fig. 6f). Because of the displacement conditions imposed on the cut-out facets of the yarns, after solving of the intermediate problems these facets occupy the same positions as when the division of the unit cell was performed. Hence the model is easily reassembled and is ready for addition of the matrix volume, final meshing, applying boundary conditions and solving of the meso-FE problem for the unit cell. Fig. $6 \mathrm{~g}$ and $\mathrm{h}$ illustrate the application of the automated procedure for the more difficult case of 3D woven structure.

The procedure described above is suited for automated processing. When the initial division of the unit cell is not performed easily (as this is the case for the three-axial braid of Table 1) and manual manipulations are needed.

Consider two interpenetrating volumes of the yarns, isolated from the whole structure manually. The intersection is corrected using the same process as above: (1) separating the yarns (moving yarns apart of each other in the thickness direction), (2) inserting separating sub-layer medium of isotropic deformable material in between the yarns (Fig. 7a and b), and then (3) returning the faces into their original position, solving a boundary value problem.
During these operations the properties of the yarns and the inserted material are not the same as the properties of the impregnated yarns and the matrix, but are assigned in a somewhat arbitrary way, to represent the yarn deformations accommodating the contact conditions. Under a certain pressure applied on the upper yarn segment, the thickness of the sub-layer is decreased to a desired clearance $c$ and the thickness of the structure after deformation is equal to the given value. Poisson coefficients of the yarns should be 0.5 to ensure the same volume of the resulting and the initial configuration. After applying the pressure, an interpenetrating configuration of the yarns is calculated (Fig. 7c and d).

Note that the presence of a thin layer of matrix in between the contacting yarns is important for successful meshing of the full meso-model. If this layer is absent, the touching yarn will form wedge-like volumes, produce degraded elements and will lead to numerical artefacts in the solution in this region.

\subsection{Meshing}

After dealing with interpenetration of volumes the model of textile composite should inherit a geometry obtained in the intermediate modelling. The latter is presented by fragmented and separated yarn geometry and mesh. The deformed FE mesh of the intermediate problem cannot be used as a mesh for the final model since the elements have changed their shape while solution and are distorted. The deformed mesh is hence transposed to the solid entities. The new volumes are generated by the deformed element configuration and then joining these volumes.

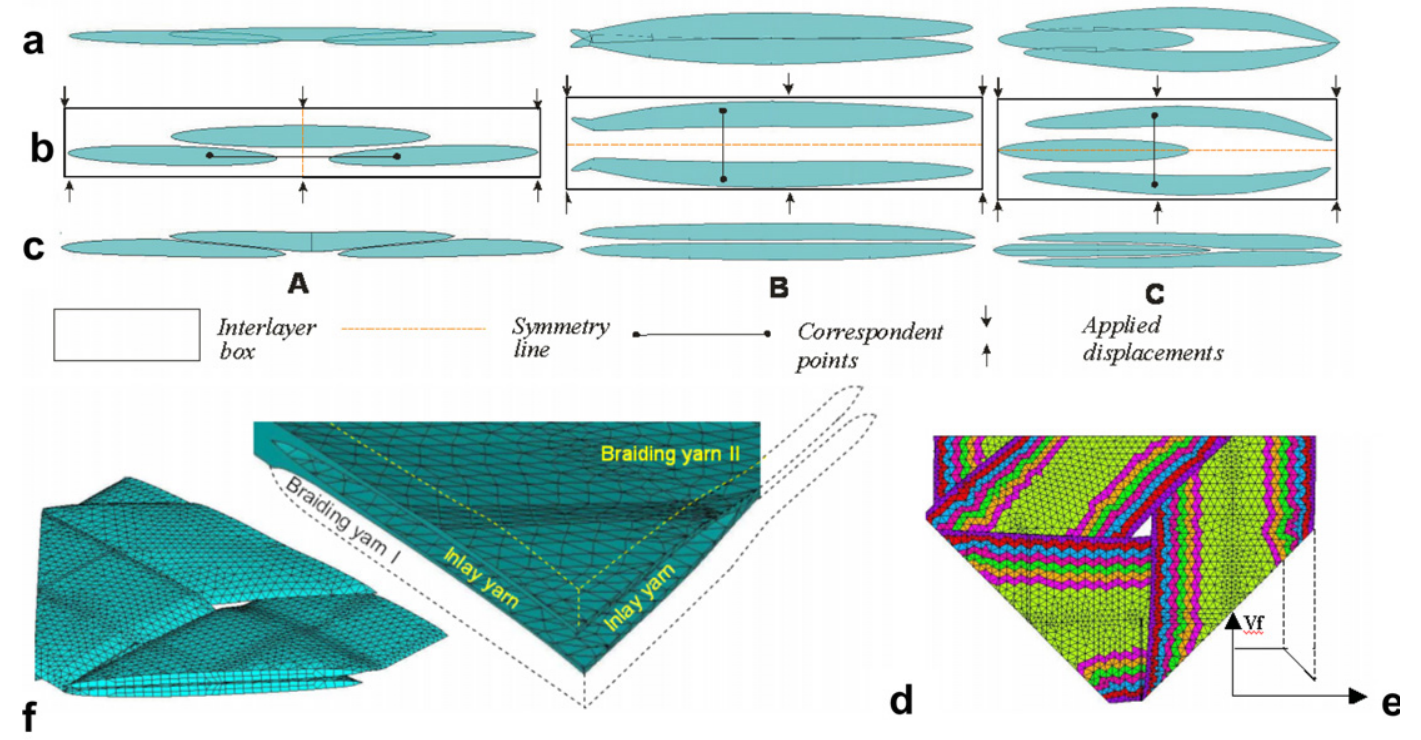

Fig. 7. Manual correction of yarn shapes (see notation for the unit cell faces in Fig. 4): (a) yarn volumes before the separation; (b) separated yarn volumes with a sub-layer between them; (c) resulting non-penetrating volumes; (d) the mesh in the yarns and the mesh in the matrix (the dashed lines show volumes of the yarns); and (e) fibre volume fraction distribution in the yarns. 
The subsequent meshing of the volumes of yarns and the matrix can be done using any meshing engine. Different strategies could be adopted: one may mesh yarn volumes first using sweeping of the planar mesh on the yarn crosssection throughout the yarn volume [45], and then build the mesh in the matrix, or rely on the quality of the mesh engine and ask it to mesh the whole unit cell volume automatically.

The latter option (automated meshing in ANSYS) was used in the example of three-axial braided composite. The element used is a 3D 20-node (three degrees of freedom per node) structural solid element (SOLID186 of ANSYS). It has quadratic displacement behaviour and is recommended for modelling irregular meshes. Prism-shaped, tetrahedral-shaped, and a pyramid-shaped element are the particular cases of this element with a reduced 10-node scheme. The element shape at a place is chosen by an automatic mesh generator. Total number of elements for the quarter of the unit cell is 64,676 , while node number is 83,739 . 12,621 nodes are involved in the constraint equations for the symmetrical boundary conditions. Total calculation time for a linear problem was about $5 \mathrm{~min}$ on Pentium IV PC.

An example of inter-yarn mesh at an intersection of three yarns (most difficult part of the mesh, where bad elements could appear) is presented in Fig. 7d. One element per interyarn clearance thickness was used. An estimation of the thickness to width ratio of the elements is about $1 /$ 3 for the thinnest part of the interyarn volume. As a result of a free meshing there are seven elements, which have high angle between the adjacent edges (in between $165^{\circ}$ and $179.9^{\circ}$ ) and one element with a high aspect ratio of about 30 . Thus the quality of the automatically generated mesh is sufficient for the further analysis.

\section{Periodic boundary conditions}

The stress-strain fields in the unit cell should have the same properties of translational symmetry as the unit cell itself. If the unit cell is characterised by translation vectors $\mathbf{b}_{1}$ and $\mathbf{b}_{2}$ (Fig. 8), then these boundary points are transformed one into another by the translation

$A^{\prime}=A+\overrightarrow{b_{1}}, \quad B^{\prime}=B+\overrightarrow{b_{2}}$.

Conditions of periodicity for a given average deformation tensor $\langle\underline{\varepsilon}\rangle$ (given by macro-conditions of the test or by local results of a macro-simulation) are [38]

$\vec{u}(A+\vec{b})-\vec{u}(A)=\langle\underline{\varepsilon}\rangle \cdot \vec{b}$

for any point $A$ on the boundary of the unit cell, and one of the translation vectors b. Note that Eq. (6) can be applied to a unit cell of any shape, including sheared unit cells of textile composite $[32,100]$ and hexagonal unit cells describing packing of unidirectional fibres [57].

Eq. (6) is easily implemented in FE packages using the apparatus of constraint equations, providing that the nodes on the opposite facets correspond one to another by (5). This means that the mesh on the opposite facets should be exactly identical, which is not necessary achieved by automatic meshing engines. Fig. 8a illustrates how to ensure the identity of the boundary meshes. The nodes of the boundary facet on one side of the unit cell are copied and assembled into shell, which is meshed. Then the unit cell is meshed; because of the previously meshed shells on the opposite facets, the mesh on the facets repeats the mesh on the shells, which is identical on both of them. After meshing the shells are deleted. Of course, the success of this procedure depends on the exact periodicity of the geometrical model of the yarns (sections of the yarn volumes on the both facets are identical).

When the model is reduced using the symmetry of the reinforcement geometry (Section 4.1), relation (6) must be rewritten. Whitcomb [34] proposed a systematic procedure for deriving boundary conditions for partial unit cells with periodic microstructure. To apply the mathematics of [34] to the example shown in Fig. 4, consider first the correspondence of points on the boundaries of $1 / 4$ of the unit cell (designated 1 in Fig. 8b), imposed by the periodicity of the full unit cell. Two periodicity vectors $\mathbf{b}_{1}$ and $\mathbf{b}_{2}$ must be accounted for.

For the periodicity in direction $\mathbf{b}_{2}$ point $A$ on the boundary of quarter of unit cell corresponds to the point $A^{\prime}$ on the opposite face of the full unit cell. Point $A^{\prime}$ is transformed into point $A^{\prime \prime}$ on the boundary of quarter of unit cell by symmetry transformation (2). Eq. (6) is rewritten for the corresponding points as

$u_{i}(A)-\gamma_{A} \alpha_{i j}^{13} u_{j}\left(A^{\prime \prime}\right)=\langle\varepsilon\rangle_{i k} b_{2 k}$,

where $u_{i}$ are components of displacement $(i, j, k=1,2,3)$, repeating indices mean summation, $\left\{\alpha_{i j}^{13}\right\}$ is the matrix of transformation of the quarters $1 \rightarrow 3$ (2), and the coefficient $\gamma_{A}= \pm 1$ ensures the equivalence of the stresses and strains on the symmetric boundaries of the unit cell (the notation used here is the same as in [34]). For the case under consideration (rotation by $\pi$ around $x_{3}$ ) the sign of $\gamma$ is chosen as follows [34]:

$$
\begin{array}{ll}
\gamma_{A}=+1 & \text { for } \sigma_{11}, \sigma_{22}, \sigma_{33}, \sigma_{12}, \\
\gamma_{A}=-1 & \text { for } \sigma_{23}, \sigma_{13} .
\end{array}
$$

The sign of $\gamma$ is +1 for components of stress/strain, which do not change their sign after applying of the symmetry transformation, and -1 otherwise. As stated in [34], certain macroscopic loadings, which include components of stresses with different $\gamma$ 's, are not compatible with the given symmetry constraints. If a given macroscopic loading includes such incompatible components, the problem should either be treated on a full unit cell, or separated into several problems with simpler loading (for example, one non-zero component) and then the solution is reconstructed by superposition.

The periodicity direction $\mathbf{b}_{1}$ presents a difficulty, as the corresponding facets of quarter of the unit cell are not on 

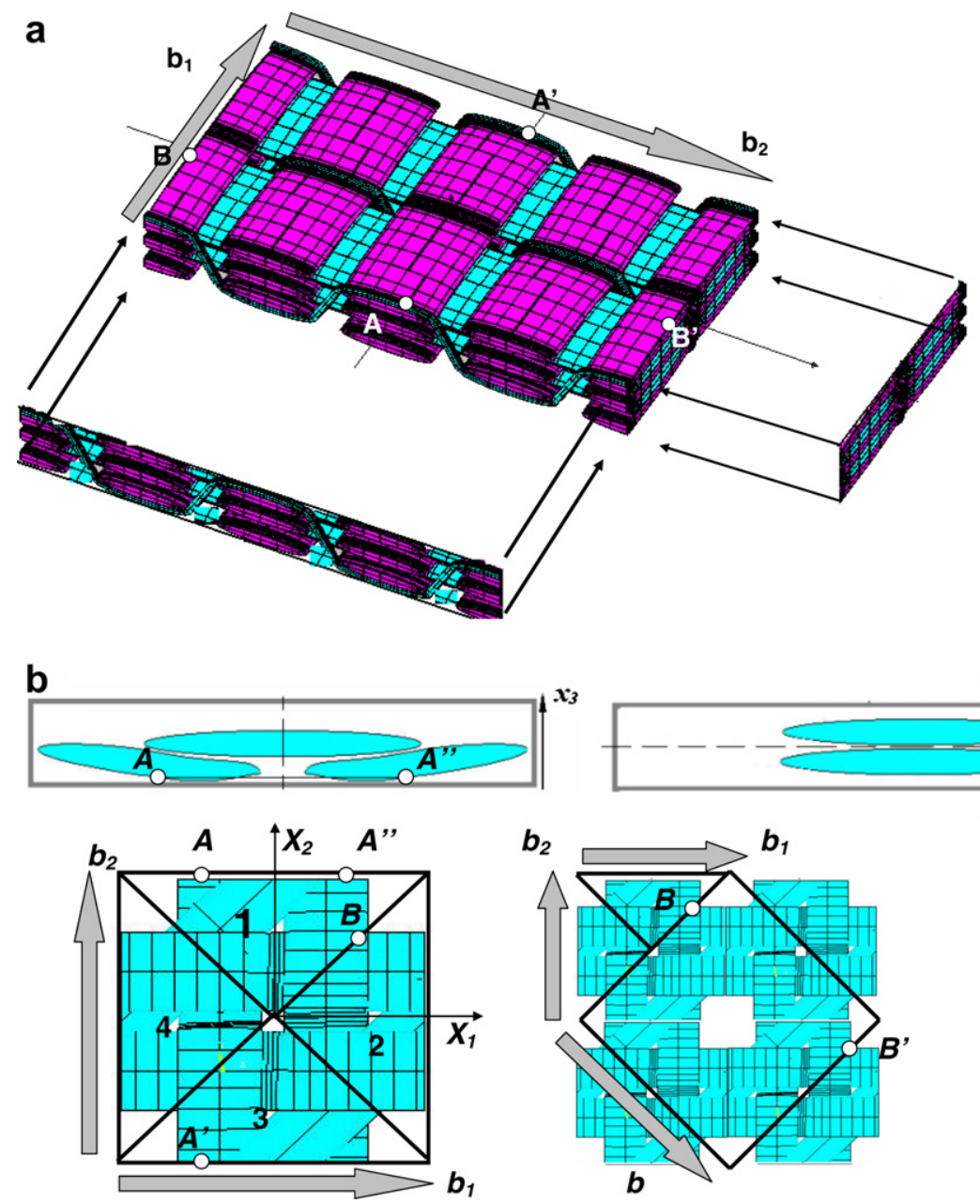

Fig. 8. Periodic boundary conditions: (a) translation vectors and corresponding points on the unit cell facets; building equal meshes on the corresponding facets and (b) corresponding points for $1 / 4$ of the unit cell.

the borders of the full unit cell. To write boundary conditions for the right-bottom facet of quarter on the unit cell (point $B$, Fig. $8 \mathrm{~b}$ ), consider another unit cell, created by translations

$\mathbf{b}=\mathbf{b}_{1}-\mathbf{b}_{2}$.

Point $B$ corresponds to $B^{\prime}$ on the opposite side of this unit cell. Point $B^{\prime}$ could be considered as belonging to the quarter 1 or quarter 2 . Only the second possibility allows accounting for the symmetry transformation. Point $B^{\prime}$ is transformed into point $B^{\prime \prime}$ on the boundary of quarter of unit cell by symmetry transformation (1). Eq. (6) is rewritten for the corresponding points as

$u_{i}(B)-\gamma_{B} \alpha_{i j}^{12} u_{j}\left(B^{\prime \prime}\right)=\langle\varepsilon\rangle_{i k} b_{k}$,

where $\left\{\alpha_{i j}^{12}\right\}$ is the matrix of transformation of the quarters $1 \rightarrow 2(1)$, and the coefficient $\gamma_{A}= \pm 1$ ensures the equivalence of the stresses and strains on the symmetric boundaries of the unit cell. For the case under consideration (rotation around $x_{1}=x_{2}$ ) the sign of $\gamma$ is chosen as follows:
$\gamma_{B}=+1$ for $\sigma_{11}, \sigma_{22}, \sigma_{33}, \sigma_{13}$

$\gamma_{B}=-1$ for $\sigma_{12}, \sigma_{23}$.

The left-bottom face of quarter of the unit cell is treated in the same manner. Note that conditions (7) and (8), in contrast to (6), relate points on the same facet of the unit cell.

\section{Material properties}

Yarns and fibrous plies are locally (on the scale of one finite element) represented as an unidirectional assembly of fibres. The direction of the fibres and the fibre volume fraction are calculated by the geometrical model as described in Section 3, accounting for the uneven distribution of fibre volume fraction in the yarns, which is an important factor for prediction of damage initiation and development [107]. Fig. 7e shows the distribution of the fibre volume fraction in the yarns of the three-axial braid, corresponding to the phenomenon of denser yarn core $[107,98]$. 

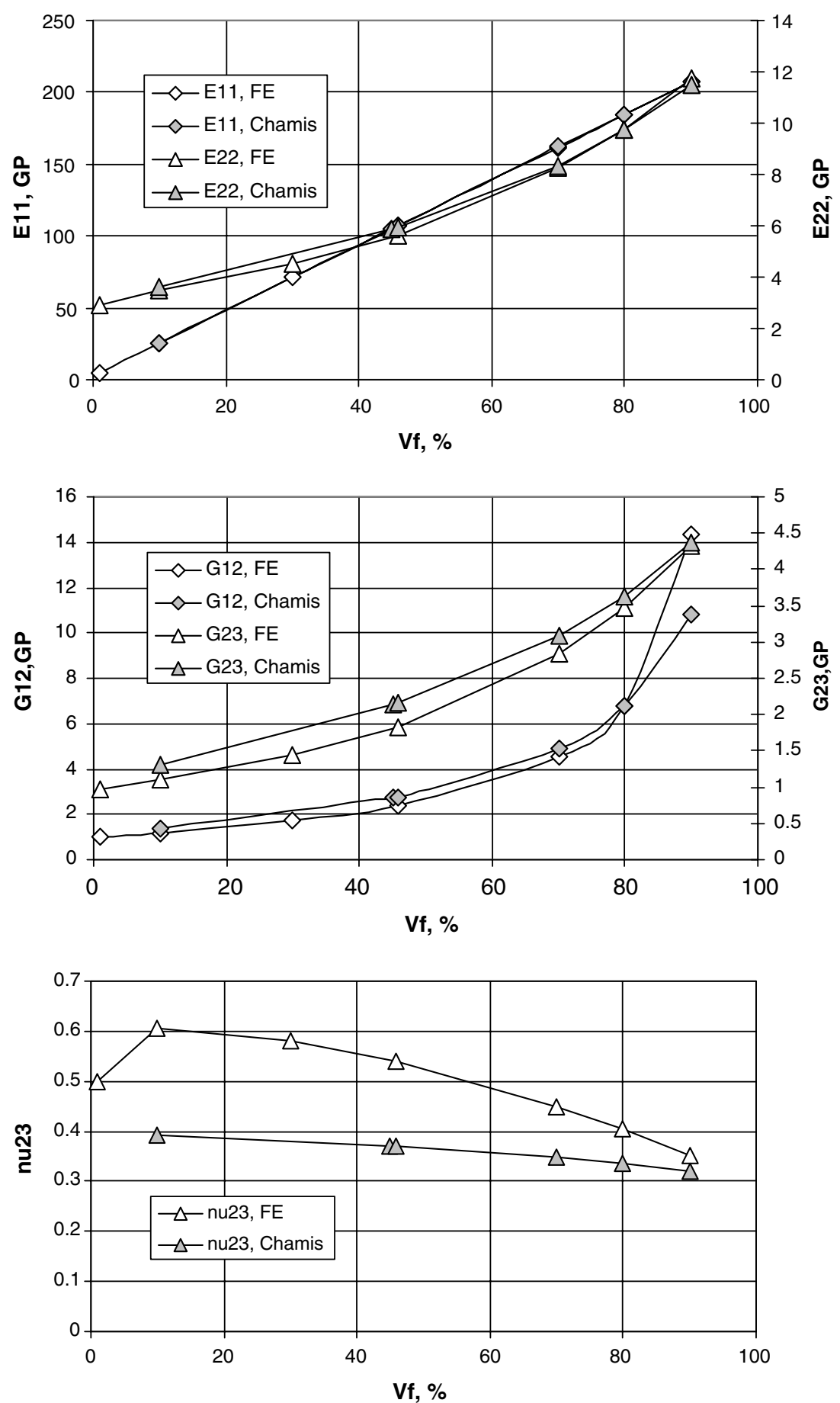

Fig. 9. Comparison of the results of micro-homogenisation by the formulae of Chamis and $\mu$-FE modelling for hexagonal packing of fibres. Fibres: carbon, $E_{1}=230 \mathrm{GPa}, E_{2}=E_{3}=28 \mathrm{GPa}, v_{23}=v_{13}=0.3, v_{31}=v_{21}=0.045, v_{12}=v_{13}=0.3$; matrix: epoxy, $E=2.73 \mathrm{GPa}, v=0.4$. Inlet: unit cell for $\mu$-FE.

The stiffness matrix of the material in the finite element is calculated using micro-meso homogenisation, based on empirical formulae $[1,115-119]$ or on micro-FE homogenisation $[38,48,57]$. The appropriate empirical formulae should be chosen according to the constituents (for example, glass/epoxy or carbon/epoxy), as the results may differ significantly [48]. Fig. 9 compares the results of homogenisation by $\mu$-FE modelling and by the formulae of Chamis [115]:

$$
\begin{aligned}
& E_{11}=V_{\mathrm{f}} E_{11}^{\mathrm{t}}+\left(1-V_{\mathrm{f}}\right) E_{\mathrm{m}}, E_{22}=E_{33}=\frac{E_{\mathrm{m}}}{1-\sqrt{V_{\mathrm{f}}}}\left(1-\frac{E_{\mathrm{m}}}{E_{22}^{\mathrm{f}}}\right), \\
& G_{12}=G_{13}=\frac{G_{\mathrm{m}}}{1-\sqrt{V_{\mathrm{f}}}\left(1-\frac{G_{\mathrm{m}}}{G_{12}^{\mathrm{t}}}\right)}, \quad G_{23}=\frac{G_{\mathrm{m}}}{1-\sqrt{V_{\mathrm{f}}}\left(1-\frac{G_{\mathrm{m}}^{\mathrm{m}}}{G_{23}}\right)}, \\
& v_{12}=v_{13}=V_{\mathrm{f}} v_{12}^{\mathrm{f}}+\left(1-V_{\mathrm{f}}\right) v_{m}, \quad v_{23}=\frac{E_{22}}{2 G_{23}}-1 .
\end{aligned}
$$


There is good agreement for the Young moduli and reasonable for the shear moduli. Small differences in $G_{13}$ lead to more pronounced difference in the Poisson ratio $v_{23}$. Formulae (9) were used for calculation of the local stiffness properties for the three-axial braid modelling.

The second set of the material properties are parameters for the criterion of damage initiation, which are calculated from the strength of the unidirectional layer of fibres under different loading conditions. The difficulty here is dependency of the strength parameters on local fibre volume fraction, which may vary in a wide range (30-90\%), which is not fully covered by the existing experimental data. Moreover the micro-mechanical damage theories are not fully validated for a 3D stress-strain state $[120,121]$. Hence, the assignment of the damage criterion parameters and their dependency of local fibre volume fraction is a question of "educated guess" at the present stage. In the absence of the experimental data the empirical approximate formulae can be used, as proposed in $[122,123]$

$$
\begin{aligned}
& F_{L}^{(\mathrm{t})}=F_{\mathrm{f}} \cdot V_{\mathrm{f}}+\left(1-V_{\mathrm{f}}\right) \cdot F_{\mathrm{m}}^{(\mathrm{t})} \cdot \frac{E_{\mathrm{m}}}{E_{\mathrm{f} L}}, \\
& F_{L}^{(\mathrm{c})}=\frac{G_{\mathrm{m}}}{1-V_{\mathrm{f}} \cdot\left(1-\frac{G_{\mathrm{m}}}{G_{\mathrm{fL}}}\right)} \\
& F_{T}^{(\mathrm{t})}=F_{\mathrm{m}}^{(\mathrm{t})} \frac{E_{T}}{E_{\mathrm{m}}} \cdot\left(1-V_{\mathrm{f}}\right), \quad F_{T}^{(\mathrm{c})}=F_{\mathrm{m}}^{(\mathrm{c})} \frac{E_{T}}{E_{\mathrm{m}}} \cdot\left(1-V_{\mathrm{f}}\right) \\
& F_{L T}=F_{\mathrm{TZ}}=F_{Z L}=\frac{1}{2} F_{T}^{(\mathrm{c})},
\end{aligned}
$$

where $F$ is the UD material strength, (t) stands for tension, (c) for compression; $L$, fibre direction; $T, Z$-transverse direction; m, matrix; f, fibre.

\section{Homogenisation}

We consider below the meso-macro homogenisation. The same may be applied to micro-meso homogenisation as well.

On the macro-scale level the composite material is considered as homogeneous, with the relation between macro strains $E$ and macro-stresses $\Sigma$, given by

$\Sigma_{i j}=C_{i j k l}^{H} \mathrm{E}_{k l}$

(here and in all the formulae in this section, the indices are in the range 1-3 and the summation rule on the repeating indexes is used; no summation on indexes in brackets). The aim of homogenisation is to find the macro-stiffness matrix $C^{\mathrm{H}}$, to be used in macro-FE analysis. On meso-level $C^{\mathrm{H}}$ is defined by the (local) internal structure of the material and properties of the constituents.

Standard approach to the problem of homogenisation is to consider the unit cell of a textile composite as a repetitive part of an infinite array of identical cells $[1,35,38,124]$. Then meso-FE modelling can be used to analyse the response of the material on the meso-level and to derive the behaviour (10). This formulation allows using periodic boundary conditions (6) for the meso-model. The main assumption of the approach is infinity of the medium and exact periodicity of the meso-geometry and the stressstrain fields, which allows using periodic boundary conditions (6).

These assumptions are not strictly applicable for the cases when the meso-geometry changes over a macro-part, or if there is a local change of the geometry, for example, damage. The former (differences of meso-geometry) normally happens over distances larger then several unit cells, and the periodicity can be considered as an approximation of real boundary conditions. The latter case cannot be treated that lightly, as periodicity assumes that the identical damage pattern is present in all the neighbouring unit cells, which does not agree with experimental observations.

To determine the effective properties of the periodic composite, six boundary value problems for a unit cell have to be solved denoted as $(i, n), i, n=1-3$. In a problem $(i, n)$ the macro strain tensor has only one non-zero component: $\left\langle\varepsilon_{k l}^{(i, n)}\right\rangle=E^{(i, n)} \delta_{i k} \delta_{n l}$, where $\langle\cdots\rangle$ is averaging over all the elements in the unit cell, $\varepsilon$ denotes meso-strain. The six problems to be solved correspond to $(i, n)=(1,1) ;(2,2) ;(3,3)$; $(1,2) ;(2,3) ;(1,3)$.

The mathematical derivation of the homogenisation formulae, based on the small parameter expansion theory, can be found in $[124,125]$. This formulation allows further generalisation for higher order theories [56]. The mathematics can be described in a condensed way as follows.

As the problem is linear, the value of $E^{(i, n)}$ is of no importance; we assume below $E^{(i, n)}=1$. The periodic boundary conditions (6) expressing continuity of the stress strain field in the periodically translated unit cells are written as follows:

$u_{k}^{i n}(A+b)-u_{k}^{i n}(A)=\delta_{i k} \delta_{n l} b_{l}=\delta_{i k} b_{n}$,

where $A$ and $A+b$ are the corresponding points on the boundaries of the unit cell.

After solution of each of the six meso-FE problems $(i, n)$ the strain tensor $\varepsilon_{p q}^{(i, n)}$ is calculated for each of the final elements of the model. The effective stiffness of the unit cell $C^{\mathrm{H}}(10)$ is then calculated by averaging [125]

$C_{k l i n}^{\mathrm{H}}=\left\langle C_{k l p q} \varepsilon_{p q}^{(i, n)}\right\rangle$,

where $C$ is stiffness of an element.

The meso-FE analysis of three-axial braid was performed using ANSYS and SACOM FE packages using two types of tetrahedral elements: quadratic (10 nodes) in ANSYS and linear (four nodes) in SACOM. ANSYS calculations were done on $1 / 8$ of the unit cell (Fig. 7), SACOM - on the full unit cell (Fig. 8b). The geometry of the mesh in both cases was exactly the same.

Table 2 shows the homogenised properties of the composite, calculated using the procedure described above. The FE-computed values (which differ for the both variants not more then $\pm 0.1 \mathrm{GPa}$ for the stiffness and by 0.01 for the Poisson coefficient) are compared with predictions of simple laminate theory calculations and with experimental 
Table 2

Homogenised properties of the three-axial braided composite

\begin{tabular}{|c|c|c|c|c|c|c|}
\hline \multirow[t]{2}{*}{ Test direction } & \multicolumn{3}{|c|}{ Young modulus (GPa) } & \multicolumn{3}{|c|}{ Poisson coefficient } \\
\hline & Experiment & FE & $\overline{\mathrm{CLT}}$ & Experiment & FE & CLT \\
\hline $0^{\circ}$ (machine) & $32.6 \pm 1.1$ & 35.9 & 36.2 & $0.73 \pm 0.06$ & 0.61 & 0.77 \\
\hline $45^{\circ}$ (braiding) & $36.8 \pm 1.8$ & 38.6 & 44.8 & $0.07 \pm 0.02$ & 0.07 & 0.07 \\
\hline $90^{\circ}$ (cross) & $15.9 \pm 0.7$ & 16.7 & 17.8 & $0.39 \pm 0.03$ & 0.33 & 0.37 \\
\hline
\end{tabular}

values, obtained with tensile testing of RTM-produced composite plates with four layers of the braided reinforcement. The laminate plate theory results were calculated for a laminate consisting of four layers. Three of them are characterised with orientation and fibre volume fraction of the yarns. The relative plies thickness was chosen according to in-plane fraction of yarn volume (volume of the braiding yarns in the unit cell is 1.414 times volume of the inlays). A matrix ply was added to balance the average volume fraction.

The FE analysis (with the detailed modelling of the composite geometry) and the rough laminate model give similar results for the overall stiffness values (the latter gives overestimation of the stiffness not more then $12 \%$ ). The need in FE analysis mainly comes from the aim to get an adequate description of the internal strain and stress state. Laminate model is unable to estimate influence of the bridging effect, yarn interaction, non-homogeneous matrix distribution and so on.

Once homogenised stiffness properties are defined, a tensile test is simulated (loading in machine-inlay direction). The average strain in machine direction is the governing parameter. Average strain in cross and thickness directions are set proportional to the governing strain according to the correspondent Poisson's ratios. Fig. 10 compares solutions with the two different FE software packages (ANSYS and SACOM), which are very close, and shows the deformations of the unit cell in the elastic regime. The applied strain of $0.3 \%$ corresponds to the onset of damage, registered using acoustic emission and full-field strain measurements.

\section{Damage modelling}

The most straightforward way for simulating damage is to base the model on fracture mechanics, directly introducing cracks in the FE model. However, it is computationally difficult to introduce free boundaries in complex textile architectures. That's why only 2D or simplified geometries (mosaic model) were tried in the framework of classical fracture mechanics [64,75]. Direct crack modelling requires a well defined crack path, which is only known in the case of delaminations [126]. Shear lag models [64,127] are known to provide reasonable prediction of the degraded stiffness, however these models require a dependence of crack density on applied strain to be known; the latter seems not to be invariant characteristics for the textile structures.

Damage mechanics approach, which is based on damage variables without introducing cracks directly into the mesh, uses well established failure criteria and relatively simple tests on strength of unidirectional composites as an input data. Furthermore, the modelling doesn't require rebuilding mesh used for an elastic analysis, and thus it is computationally simple. The approach is widely used for textile composites $[63,68,71,73,76,128]$. Most of known damage mechanics approaches are local, i.e. the decision of the damage initiation in an element is made based on a

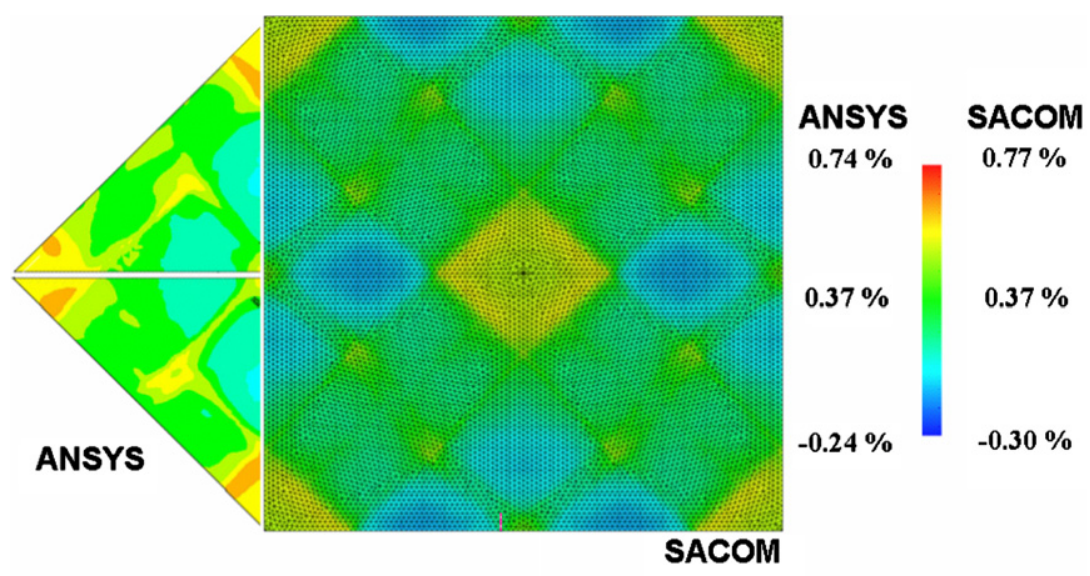

Fig. 10. Linear meso-FE analysis of three-axial braid, strain in the machine direction (direction of loading): comparison of the ANSYS and SACOM solutions. 
criterion, which uses stress components in the element only (criteria of Tsai-Hill, Hoffman, maximum stress, etc.). The local stiffness of damaged elements is then zeroed or reduced. Whitcomb and Srirengan [71] show that local damage algorithm may be sensitive to number of elements, element interpolation order (linear or quadratic), and the scheme of property degradation. Nevertheless there are no an ultimate alternative to the local approach as the current state of the art stays. Fish [72] has proposed a nonlocal damage model for a satin weave composite with ceramics matrix, where the latter can be damaged, while bundles can not. However, a need of fitting experimental data brings the model back to a phenomenological description.

When a damage mechanics approach is adopted, several decisions must be made for meso-FE modelling of damage: (1) choice of the damage initiation criteria, (2) formulae for decrease of the stiffness of the damaged elements and (3) algorithm for damage propagation. Damage initiation criteria, applied on micro-level, treat yarns and fibrous plies locally as unidirectional composites, hence the whole selection of criteria, analysed and benchmarked during world wide failure exercise (WWFE) [129] could be used. There is no single choice, as even the criteria top-ranked by WWFE were validated fully for 2D stress-strain conditions only, and may deviate from the real behaviour for 3D loading $[120,121]$. Existing formulae for the decrease of stiffness after damage and damage propagation have several weak points, the most important being the arbitrary choice of constants for deterioration of properties and possible mesh dependency of the damage propagation process.

In this section we give, as one of the possible approaches, the formulae implemented in the SACOM software [76] and used in calculations both with SACOM and ANSYS in the three-axial braid example. The models, before application to textile composites $[65,76]$ were tested for laminates [103], including a mesh dependency study (it has been shown, for the case of damage in laminates, that the dependency of the damage propagation rate on the number of elements is weak) [130] and plates with a circular hole [131].

Hoffman's failure criterion [132] is used in SACOM to assess the damage initiation, with addition of indication of the damage mode, which affects strongly the mechanical behaviour. The damage modes of fibres can be classified into four types as shown in Table 3. The axes $L, T$ and $Z$ mean the principal coordinates of orthotropic material, and they correspond to fibre and transverse directions, respectively, determined locally for each finite element. The mode $L$ represents the fibre breaking; the others represent the transverse and shear cracking. The choice of the damage mode is defined by stress components corresponding to damaged configuration (normal stress $L, T$ and $Z$ and shear stress $T Z, Z L$ and $L T$ ). Damage in one of the modes is registered when one of the stress indices in Table 3 reaches value 1 :

$H_{X}=1, \quad$ where $X=L, T, Z, L T, L Z$.
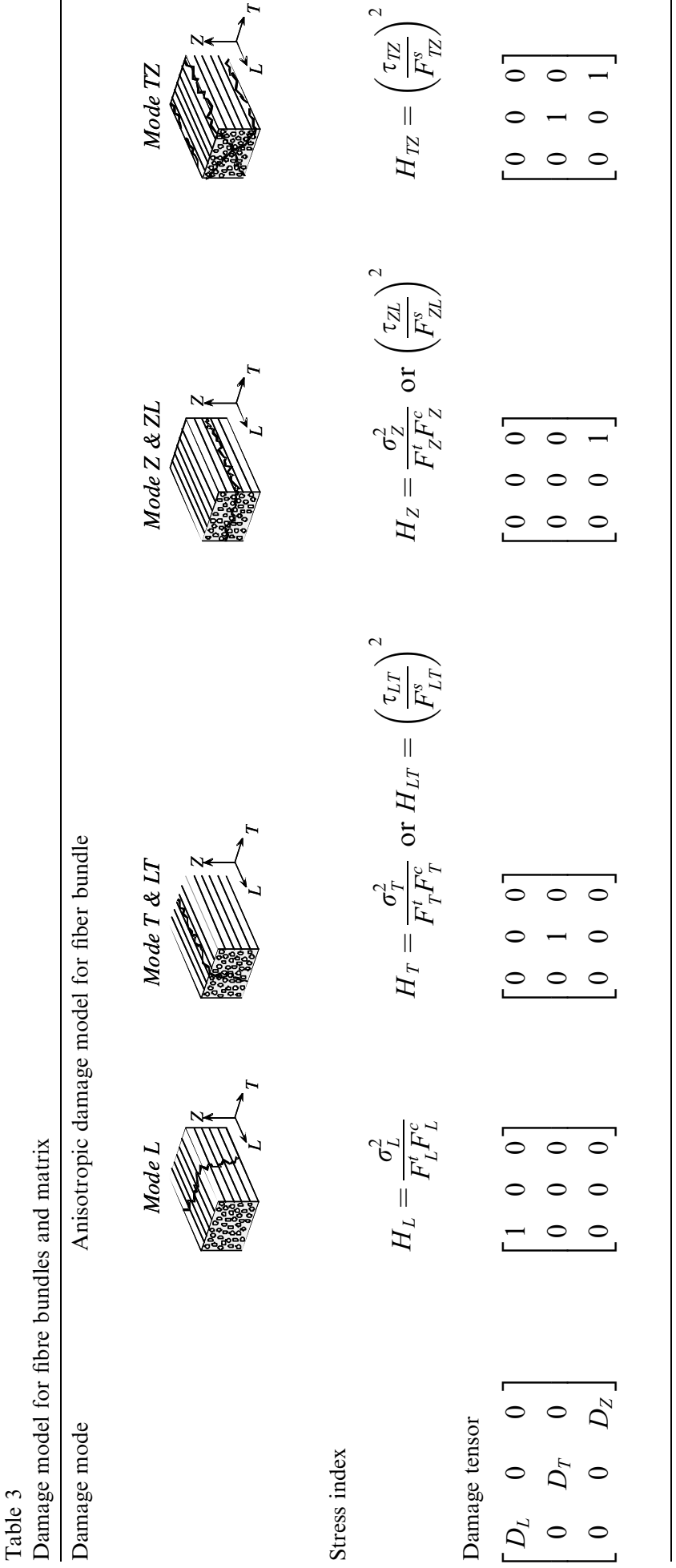
The parameters $F^{\mathrm{t}}, F^{\mathrm{c}}$ and $F^{\mathrm{s}}$ indicate the tensile, compressive and shear strengths, respectively. The values of these parameters are defined experimentally for unidirectionally reinforced composites.

For the damage characterisation the Murakami's damage tensor [133] is adopted:

$\boldsymbol{D}=\sum_{X} D_{X} n_{X} \otimes n_{X} \quad(X=L, T, Z)$

where $D_{i}$ and $n_{i}$ are the principal value and principal unit vector of the damage tensor. We use only the diagonal components

$[D]=\left[\begin{array}{ccc}D_{L} & 0 & 0 \\ 0 & D_{T} 0 & \\ 0 & 0 & D_{Z} .\end{array}\right]$

The damage factors $D_{X}$ may take arbitrary values within the range from 0 to 1 . The formulation with only two values, 0 for initial undamaged state or 1 for full damaged state, is used here and the corresponding damage tensors for the four modes are given in Table 3. For the matrix the isotropic damage model is used.

The constitutive equation for the damaged composite materials can be derived using the effective stress in the undamaged configuration. That is, we define the effective stress $\sigma^{*}$ by the actual stress in the damaged configuration $\sigma$ (symmetric tensor):

$\sigma^{*}=\frac{1}{2}\left[(\boldsymbol{I}-\boldsymbol{D})^{-1} \sigma+\sigma(\boldsymbol{I}-\boldsymbol{D})^{-1}\right]=\boldsymbol{M}(\boldsymbol{D}) \sigma$

and the constitutive equation of the damaged material is defined as follows:

$\varepsilon=\boldsymbol{C}(\boldsymbol{D}) \sigma$,

where $\varepsilon$ is the actual strain vector in the damaged configuration. $\boldsymbol{C}(\boldsymbol{D})$ is derived by the notion of energy identification [134].

$\boldsymbol{C}(\boldsymbol{D})=(\boldsymbol{M}(\boldsymbol{D}))^{\mathrm{T}} \cdot \boldsymbol{C}_{0} \cdot \boldsymbol{M}(\boldsymbol{D})$,

where $\boldsymbol{C}_{0}$ is the elastic tensor for the undamaged configuration.

Eqs. (16) and (17) can be represented in matrix/vector form as

$\left\{\sigma_{L T Z}\right\}=\left[Q_{L T Z}^{*}\right]\left\{\varepsilon_{L T Z}\right\}$,

where the equivalent stiffness matrix $\left[Q_{L T Z}^{*}\right]$ is expressed by using the stiffness matrix of the initial state $\left[Q_{L T Z}\right]$ and the principal values of the damage tensor $D_{i}$ : where the parameters $Q_{i j}$ are the components of the stressstrain matrix for the initial state and the parameters $d_{i}$ are defined as follows:

$$
\left.\begin{array}{l}
d_{L}=1-D_{L}, \quad d_{T}=1-D_{T}, \quad d_{Z}=1-D_{Z} \\
d_{T Z}=\left(\frac{2 d_{T} d_{Z}}{d_{T}+d_{Z}}\right)^{2}, \quad d_{Z L}=\left(\frac{2 d_{Z} d_{L}}{d_{Z}+d_{L}}\right)^{2}, \quad d_{L T}=\left(\frac{2 d_{L} d_{T}}{d_{L}+d_{T}}\right)^{2}
\end{array}\right\}
$$

The damage factors $D_{i}$ change from 0 at the initial undamaged state to 0.99 (slightly less then 1.0 for numerical stability reasons) at fully damaged state when the occurrence of damage is detected by Hoffman's criterion.

This formulation enables the simulation of the mechanical behaviour after the occurrence of damage based on the damage modes and the loading conditions. The non-linear behaviour is calculated by the incremental displacement method. At first, damaged elements are caught by Hoffman's criterion, and damage modes are determined from damage indices $H_{X}$. Second, the stiffness of damaged elements is reduced by the above formulation, and anisotropic damaged states are reflected in the new global stiffness matrix. Third, the global system of equations of elasticity is solved again without increase of applied displacement, and the redistributed stresses after damage are calculated. Finally, the above process is repeated until no damaged elements are detected, and we shift to the next step with increase of the applied displacement.

Table 4 shows the assumed strength parameters of the impregnated yarns (unidirectional composite) and the matrix. In the absence of reliable data on the dependency of the strength properties on the local fibre volume fraction in the impregnated yarns, the strength parameters were assumed to be the same everywhere in the yarn. The critical values of the transverse and shear strength correspond to

Table 4

Parameters of the damage models for the yarns in the three-axial braid composite

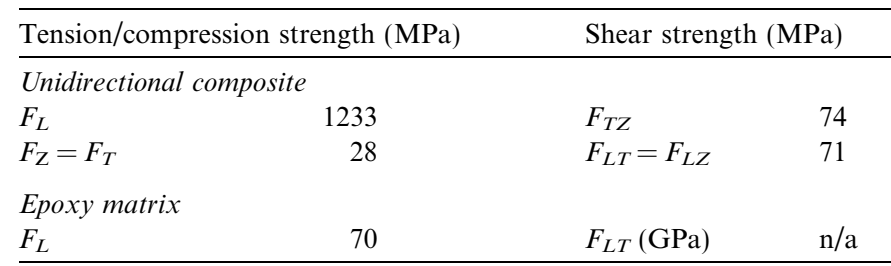

$$
\left\{\begin{array}{c}
\sigma_{L} \\
\sigma_{T} \\
\sigma_{Z} \\
\tau_{T Z} \\
\tau_{Z L} \\
\tau_{L T}
\end{array}\right\}=\left[\begin{array}{cccccc}
d_{L}^{2} Q_{11} & d_{L} d_{T} Q_{12} & d_{Z} d_{T} Q_{13} & 0 & 0 & 0 \\
& d_{T}^{2} Q_{22} & d_{T} d_{Z} Q_{23} & 0 & 0 & 0 \\
& & d_{Z}^{2} Q_{33} & 0 & 0 & 0 \\
& & & d_{T Z} Q_{44} & 0 & 0 \\
& \text { sym. } & & & d_{Z L} Q_{55} & 0 \\
& & & & & d_{L T} Q_{66}
\end{array}\right\} \quad\left\{\begin{array}{c}
\varepsilon_{L} \\
\varepsilon_{T} \\
\varepsilon_{Z} \\
\gamma_{T Z} \\
\gamma_{Z L} \\
\gamma_{L T},
\end{array}\right\}
$$



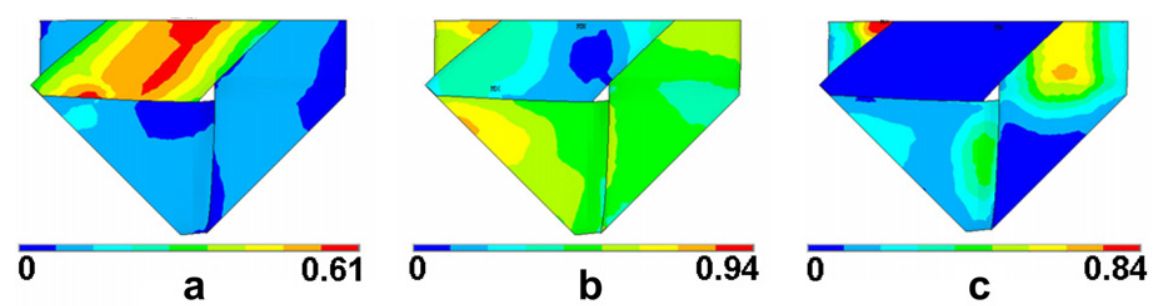

Fig. 11. Stress index I three-axial braided composite under tension in the machine direction, applied strain $0.3 \%$ : (a) longitudinal $H_{L} ;$ (b) transverse $H_{T}$; and (c) shear $H_{L T}$.

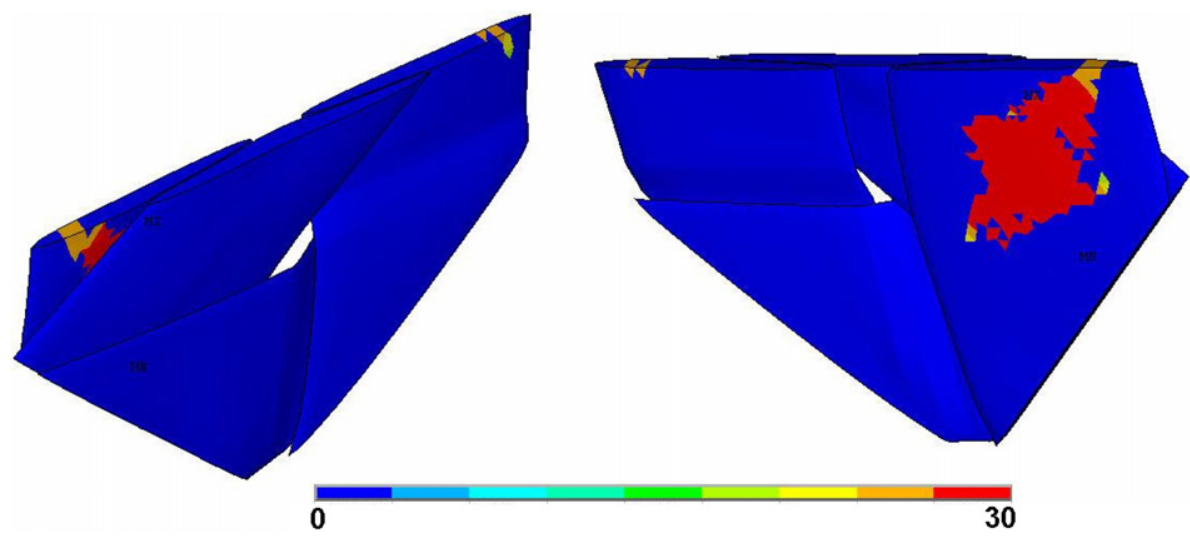

Fig. 12. Damage development in three-axial braided composite: scale defines load step when damage occurs; maximum corresponds to the earliest stage.

experimental data on UD plies for fibre volume fraction range $40-60 \%$.

As mentioned before, acoustic emission, full-field strain measurements and and X-ray investigation indicate onset of damage in the three-axial braided composite under tension in the machine direction at the applied strain of $0.3 \%$. Fig. 11 shows the stress indices according to the Hoffman criterion (Table 3). The maximum value of the index $H_{T}=0.94$, hence the applied strain of $0.3 \%$ is close to the theoretical damage initiation strain. The damage is caused by transversal tensile stresses. Fig. 12 shows that the damage starts in the braiding yarn, lying at $45^{\circ}$ to the loading direction, which corresponds to the X-ray observation of the damage.

Good predictions of the onset of damage in textile composites (analogue to the "first ply failure" in laminates) has been shown in a number of publications $[62,63,66,68]$. Whitcomb [71] notes dependency of meso-FE analysis of progressive failure in woven composites on the type of the finite elements and the mesh refinement.

We have calculated the damage onset threshold in the three-axial braided composite for the following variants: (1) ANSYS and SACOM calculations with quadratic and linear elements correspondingly; (2) mesh finesse (number of elements) different by a factor of 2 . For all the variants the damage initiation strain, predicted by Hoffmann criterion, varied in the range of $0.3 \pm 0.02 \%$. This shows robustness of the damage detection algorithm.
However, when it comes to the damage propagation, the calculations show non-physical behaviour (Fig. 12). The damage propagates along the yarn, in the direction of the fibres, as one expects and as it is observed in experiments, but it also propagates across the yarn, suggesting a multitude of micro-cracks, which is not observed in experiment (there are one-two well-separated cracks over the whole yarn width). This seems to be a common drawback for meso-FE modelling of damage which use local damage criteria and properties degradation scheme, as the same effect is observed in calculation reported in $[62,66,68]$. The reasons of this behaviour are not clear, and will be a subject of further investigations. For isotropic material the similar effects are discussed in $[73,135,136]$.

\section{Conclusions}

We have presented an orderly approach to meso-FE modelling of textile composites. It makes clear that integrated modelling systems are in the order of the day, being ready to emerge in the coming years. Such a system will be suitable not only for academic research and illustration of principles, but also for serious treatment of practically important textile composites with complex architecture, and allowing rapid variation of the reinforcement structural parameters and mechanical properties of the constituents, using user friendly interface and adequate results both for linear and non-linear, damaged behaviour. An 
integrated FE-modeller should include the following modules:

- A geometric modeller, which defines the volumes of yarns and fibrous plies in the unit cell of textile composite, local fibre parameters on the micro-scale and provides interface with FE package to export these data.

- A geometry corrector, which adapts the geometrical model for requirements of the meshing engine and the particular necessities of boundary conditions formulation process.

- A meshing engine.

- A material property processor, which assigns material properties to volumes/elements, using local fibre assembly parameters on micro-scale, provided by the geometrical model, and applying a certain model of homogenisation on micro-level, or even a menu for user choice of such a model.

- Boundary conditions routines, facilitating posing periodic boundary conditions.

- A FE-solver and post-processor.

- A homogenisation engine, which automatically applies the necessary loading and boundary condition, processes the results and outputs homogenised meso-stiffness matrix of the textile composite.

- A damage detection processor, employing one of (userchosen) damage initiation criteria.

- A damage development processor, responsible for monitoring the damage tensor, change of the homogenised (on micro-level) properties and decisions on the damage propagation modelling.

Based on the geometrical modeller WiseTex, commercial ANSYS and custom-developed SACOM FE packages, we have developed an integrated system, which includes all the modules, listed above. They constitute a solid basis for future work, leading to meso-FE modelling systems, integrated with macro-FE structural analysis and $\mu$-FE analysis of fine features of damage.

\section{Acknowledgements}

The work in K.U. Leuven was supported by European Comission (ITOOL project), government of Flanders (IWT-GBOU project "Predictive tools for permeability, mechanical and electro-magnetic properties of fibrous assemblies") and the Research Council of K.U. Leuven (OT project "Concurrent multi-scale design/engineering of textile composites" and East-European Ph.D. grant of D.S. Ivanov).

\section{References}

[1] Bogdanovich AE, Pastore CM. Mechanics of textile and laminated composites. London: Chapman \& Hall; 1996.

[2] Tsai SW. Theory of composites design. Dayton: Think Composites; 1992.
[3] Leischner U, Johnson AF. Micromechanical analysis of hybrid woven fabric composites under tensile and compression load. J Compos Mater Technol 1994;4:387-405.

[4] Cox BN, Flanagan G. Handbook of analytical methods for textile composites. Hampton (VA): National Aeronautics and Space Administration, Langley Research Center; 1997.

[5] Bigaud D, Dreano L, Hamelin P. Models of interactions between process, microstructure and mechanical properties of composite materials - a study of the interlock layer-to-layer braiding technique. Compos Struct 2005;67:99-114.

[6] Bogdanovich AE. Three-dimensional analysis of anisotropic spatially reinforced structures. Compos Manuf 1993;4(4): 173-86.

[7] Bogdanovich AE, Pastore CM. An hierarchical three-dimensional analysis of textile composite plates. In: Int Mech Eng Congr. Chicago: ASME; 1994. p. 1-12.

[8] Bogdanovich AE, Pastore CM. On the structural analysis of textile composites. In: Birman V, Nagar A, editors. Topics in composite materials and structures. New York: ASME; 1992. p. 1-19.

[9] Bogdanovich AE, Pastore CM, Birger AB. Three-dimensional deformation and failure analysis of textile reinforced composite structures. In: Miravete A, editor. Composites design: proceedings of the 9th international conference on composite materials (ICCM9). Madrid: University of Zaragoza; 1993. p. 495-501.

[10] Bogdanovich AE, Pastore CM. Material-smart analysis of textilereinforced structures. Compos Sci Technol 1996;56:291-309.

[11] Pastore CM, Bogdanovich AE. Applications of a meso-volumebased analysis for textile. Compos Struct Compos Eng 1993;3(2):181-94.

[12] Prodromou A. Mechanical modelling of textile composites utilising a cell method, in Department MTM. Leuven: K.U. Leuven; 2004. p. 149.

[13] Aboudi J. Micromechanical analysis of composites by the method of cells. Appl Mech Rev 1989;42:193-221.

[14] Vandeurzen P. Structure-performance modelling of two-dimensional woven fabric composites in Dept. MTM. Leuven: K.U. Leuven; 1998.

[15] Vandeurzen P, Ivens J, Verpoest I. Micro-stress analysis of woven fabric composites by multilevel decomposition. J Compos Mater 1998;32(7):623-51.

[16] Huang Z-M, Ramakrishna S. Towards automatic designing of 2D biaxial woven and braided fabric composites. J Compos Mater 2002;36(13):1541-79.

[17] Miravete A. 3D reinforcements in composite materials. Cambridge: Woodhead; 1999. p. 308.

[18] Cox BN, Dadkhan MS. The macroscopic elasticity of 3D woven composites. J Compos Mater 1995;29(6):785-819.

[19] Cox BN, Carter WC, Fleck NA. A binary model of textile composites: I Formulation. Acta Mater 1994;44(10):3463-79.

[20] Yushanov SP, Bogdanovich AE, Mohamed MH. Manufacturing and property analysis of a novel class of 3D woven composites. In: Gibson RF, Newaz GM, editors. Proceedings of the american society for composites. 12th technical conference. Deadborn (MI): Technomic; 1997. p. 995-1004.

[21] Yushanov SP, Bogdanovich AE, Mohamed MH. Manufacturing and property analysis of a novel class of 3D woven composites. J Thermoplast Compos Mater 1999;12(1):70-82.

[22] Naik RA, Ifju PG, Masters JE. Effect of fibre architecture parameters on deformation fields and elastic moduli of $2 \mathrm{D}$ braided composites. J Compos Mater 1994;28:656-80.

[23] Naik NK. Woven fabric composites. Lancaster (Basel): Technomic; 1994. p. 192.

[24] Naik NK, Azad SNM, Durga Prasad P, Thuruthimattam BJ. Stress and failure analysis of $3 \mathrm{D}$ orthogonal interlock woven composites. J Reinf Plast Compos 2001;20(17):1485-523.

[25] Naik NK, Kuchibhota R. Analytical study of strength and failure behaviour of plain weave fabric composites made of twisted yarns. Composites, Part A 2002;33:697-708. 
[26] Pastore CM, Ko FK. Modelling of textile structural composites. Part I: Processing-science model for three-dimensional braiding. J Textile Inst 1990;81(4):480-90.

[27] Sun H-Y, Qiao X. Prediction of the mechanical properties of threedimensionally braided composites. Compos Sci Technol 1997;57:623-9.

[28] Buyn J-H. The analytical characterisation of 2D braided textile composites. Compos Sci Technol 2000;60:705-16.

[29] Huysmans G, Verpoest I, Van Houtte P. A damage model for knitted fabric composites. Composites, Part A 2001;32(10): 1465-75.

[30] Huysmans G, Verpoest I, Van Houtte P. A poly-inclusion approach for the elastic modelling of knitted fabric composites. Acta Mater 1998;46(9):3003-13.

[31] Huysmans G. Unified micromechanical models for textile composites, in Department MTM. Leuven: K.U. Leuven; 2000.

[32] Lomov SV, Bernal E, Ivanov DS, Kondratiev SV, Verpoest I. Homogenisation of a sheared unit cell of textile composites: FEA and approximate inclusion model. Revue européenne des éléments finis 2005;14(6-7):709-28.

[33] Tang X, Whitcomb JD. General techniques for exploiting periodicity and symmetries in micromechanics analysis of textile composites. J Compos Mater 2003;37(13):1167-89.

[34] Whitcomb J, Chapman CD, Tang X. Derivation of boundary conditions for micromechanics analyses of plain and satin woven composites. J Compos Mater 2000;34(9):724-47.

[35] Whitcomb J, Srirengan K, Chapman C. Evaluation of homogenization for global/local stress analysis of textile composites. Compos Struct 1995;31:137-49.

[36] Karkkainen RL, Sankar BV. A direct micromechanics method for analysis of failure initiation of plain weave textile composites. Compos Sci Technol 2006;66:137-50.

[37] Bigaud D, Hamelin P. From geometrical description to mechanical prediction - application to woven fabric composites. Sci Eng Compos Mater 1998;7(4):291-8.

[38] Carvelli V, Poggi C. A homogenization procedure for the numerical analysis of woven fabric composites. Composites, Part A 2001;32(10):1425-32.

[39] Crookston JJ, Robitaille F, Long AC, Rudd CD, Ooi J. A systematic study of the mechanical properties of textile composite unit cells based on geometrical modelling. In: Proceedings ICCM-14, CD ed., San Diego, 2003.

[40] D'Amato E. Analysis of nonlinearities in mechanical behaviour of textile composites. In: Brebbia CA, de Wilde WP, editors. High performance structures and composites. Southampton (Boston): WIT Press; 2002. p. 501-10.

[41] Hale RD, Villa M. Influence of opposing wave nesting in compression-loaded composites. J Compos Mater 2003;37(13): 1149-66.

[42] Hivet G, Laine B, Boisse P. Consistent preprocessor for the unit woven cell for meso-macro analyses of fabric forming. In: Proceedings of the 8th ESAFORM conference on material forming, ClujNapoca, 2005. p. 947-50.

[43] Lee CS, Chung SW, Shin H, Kim SJ. Virtual material characterization of 3D orthogonal woven composite materials by large-scale computing. J Compos Mater 2005;39(10):851-63.

[44] Lomov SV, Ding X, Hirosawa S, Kondratiev SV, Molimard J, Nakai $\mathrm{H}$, et al. FE simulations of textile composites on unit cell level: validation with full-field strain measurements. In: Proceedings 26th SAMPE-Europe conference, Paris, 2005. p. 28-33.

[45] Lomov SV, Verpoest I, Kondratiev SV, Borovkov AI. An integrated model strategy for processing and properties of textile composites: new results. In: Griffith GR, McCarthy RFJ, editors. Proceedings of the 22nd international SAMPE Europe conference. Paris: SAMPE; 2001. p. 379-89.

[46] Potluri P, Manan A. Geometrical and micro-mechanical modelling of braided composite tubes. In: Proceedings ICCM-14, CD ed., San Diego, 2003.
[47] Quek SC, Waas A, Shahwan KW, Agaram V. Compressive response and failure of braided textile composites: Part 2 - computations. Int J Non-Linear Mech 2004;39(4):649-63.

[48] Searles K, Obegard G, Kumosa M. Micro- and mesomechanics of 8-harness satin woven fabric composite. I. Evaluation of elastic behaviour. Composites, Part A 2001;32:1627-55.

[49] Tan P, Tong L, Steven GP. Micromechanics models for mechanical and thermomechanical properties of 3D through-the thickness angle interlock woven composites. Composites, Part A 1999;30:637-48.

[50] Woo K, Suh YW. Low degree of homogenity due to phase shift for woven composites. J Compos Technol Res 2001;23(4):239-46.

[51] Woo K, Whitcomb JD. A post-processor approach for stress analysis of woven textile composites. Compos Sci Technol 2000;60:693-704.

[52] Yang Q, Cox B. Predicting local strains in textile composites using the binary model formulation. In: Proceedings ICCM-14, CD ed., San Diego, 2003.

[53] Bahei-El-Din YA, Rajendran AM, Zikry MA. A micromechanical model for damage progression in woven composite systems. Int $\mathbf{J}$ Solids Struct 2004;41:2307-30.

[54] Bigaud D, Hamelin P. Stiffness and failure modelling of 2D and 3D textile-reinforced composites by means of imbricate-type elements approaches. Comput Struct 2002;80:2253-64.

[55] Zhou G, Sun X, Wang Y. Multi-chain digital element analysis in textile mechanics. Compos Sci Technol 2004;64:239-44.

[56] Ivanov DS, Lomov SV, Verpoest I. Zero and first order homogenisation schemes: comparison with a full FE model. In: Proceedings of the 7th international conference on textile composites (TexComp7), Yonezawa (Textile 15), 2004. p. 1-4.

[57] Carvelli V, Talierico A. A micromechanical model for the analysis of unidirectional elastoplastic composites subjected to 3D stresses. Mech Res Commun 1999;26(5):547-53

[58] Peng X, Cao J. A dual homogenisation and finite element approach for material characterisation of textile composites. Composites, Part B 2002;33:45-56.

[59] Whitcomb J, Tang X. Effective moduli of woven composites. J Compos Mater 2001;35(23):2137-44.

[60] Zeman J, Sejnoha M. Homogenization of balanced plain weave composites with imperfect microstructure: Part I - Theoretical formulation. Int J Solids Struct 2004;41:6549-71.

[61] Crookston JJ, Long AC, Jones IA. A summary review of mechanical properties prediction methods for textile reinforced polymer composites. Proc Inst Mech Eng, Part L - J Mater Des Appl 2005;219(L2):91-109.

[62] Nicoletto G, Riva E. Failure mechanisms in twill weave laminates: FEM predictions vs experiments. Composites, Part A 2004:35:787-95.

[63] Carvelli V, Poggi C. A numerical approach for the failure analysis of textile composites. In: Proceedings ICCM-14, CD ed., San Diego, 2003.

[64] Edgren F, Mattsson D, Asp LE, Varna J. Formation of damage and its effects on non-crimp fabric reinforced composites loaded in tension. Compos Sci Technol 2004;64:675-92.

[65] Kurashiki T, Zako M, Hirosawa S, Imura M, Lomov SV, Verpoest I. A numerical simulation of woven fabric composites by FEM based on damage mechanics. In: Proceedings of the 15th international conference on composite materials (ICCM-15), CD ed., Durban, 2005

[66] Kurashiki T, Zako M, Verpoest I. Damage development of woven fabric composites considering an effect of mismatch of lay-up. In: Sol H, Degrieck J, editors. Composites for the future. Proceedings 10th European conference on composite materials (ECCM-10), CD ed., Brugge, 2002.

[67] Nakai A, Osada T, Fukui T, Inoda M. Initial fracture behaviour of knitted composites. In: Proceedings of 7 th Japan international SAMPE symposium \& exhibition. November 13-16, Tokyo, 2001. p. 733-6. 
[68] Tang X, Whitcomb JD. Progressive failure behaviour of 2D woven composites. J Compos Mater 2003;37(14):1239-59.

[69] Uetsuji Y, Zako M, Nishiyabu K. Numerical analysis and in situ SEM observation of damage development for woven fabric composite materials. J Soc Mater Sci - Japan 2002;51(10): $1147-53$

[70] Tabiei A, Ivanov I. Material and geometrically non-linear woven composite micro-mechanical model with failure for finite element simulations. Int J Non-Linear Mech 2004;39:175-88.

[71] Whitcomb J, Srirengan K. Effect of various approximations on predicted progressive failure in plain weave composites. Compos Struct 1996;34:13-20.

[72] Fish J, Yu Q, Sheck KL. Computational damage mechanics for composite materials based on mathematical homogenization. Int $\mathbf{J}$ Numer Meth Eng 1999;45(11):1657-79.

[73] Fish J, Yu Q. Two-scale damage modeling of brittle composites. Compos Sci Technol 2001;61:2215-22.

[74] Sun X, Sun C. Mechanical properties of three-dimensional braided composites. Compos Struct 2004;65:485-92.

[75] Le Page BH, Guild FJ, Ogin SL, Smith PA. Finite element simulation of woven fabric composites. Composites, Part A 2004;35:861-72.

[76] Zako M, Uetsuji Y, Kurashiki T. Finite element analysis of damaged woven fabric composite materials. Compos Sci Technol 2003;63:507-16.

[77] Lomov SV, Van den Broucke B, Tumer F, Verpoest I, De Luka P, Dufort L. Micro-macro structural analysis of textile composite parts. In: Proceedings ECCM-11, CD ed., Rodos, 2004.

[78] Zako M, Hayashi S, Kurashiki T, Kubo F. Thermal stress analysis by mesh superposition method. Trans Jpn Soc Mech Eng 2003;69(9):1325-30.

[79] Van den Broucke B, Tumer F, Lomov SV, Verpoest I, De Luka P, Dufort L. Micro-macro structural analysis of textile composite parts: case study. In: Proceedings of the 25th international SAMPE Europe conference, March 30th-April 1st, Paris, 2004. p. 194-9.

[80] Takano N, Okuno Y. Three-scale finite element analysis of heterogeneous media by asymptotic homogenisation and mesh superposition method. Int J Solids Struct 2004;41(15):4121-35.

[81] Takano N, Zako M, Ishizomo M. Milti-scale computational method for elastic bodies with global and local heterogenity. J ComputAided Mater Des 2000;7:111-32.

[82] Takano N, Zako M, Okazaki T. Local and microscopic analysis of woven fabric composite material under bending by finite element mesh superposition method. In: Proceedings of 7th Japan international SAMPE symposium \& exhibition, Tokyo, November 13-16, 2001. p. 725-8.

[83] Verpoest I, Lomov SV. Virtual textile composites software Wisetex: integration with micro-mechanical, permeability and structural analysis. Compos Sci Technol 2005;65(15-16):2563-74.

[84] Boisse P, Borr M, Buet K, Cherouat A. Finite element simulations of textile composite forming including the biaxial fabric behaviour. Composites, Part B 1999;28B:453-64.

[85] Boisse P, Buet K, Gasser A, Launay J. Meso/macro-mechanical behaviour of textile reinforcements for thin composites. Compos Sci Technol 2001;61:395-401.

[86] Gasser A, Boisse P, Hanklar S. Analysis of the mechanical behaviour of dry fabric reinforcements. 3D simulations versus biaxial tests. Computat Mater Sci 2000;17:7-20.

[87] Hivet G, Boisse P. Consistent 3D geometrical model of fabric elementary cell. Application to a meshing preprocessor for 3D finite element analysis. Finite Elements Anal Des 2005;42:25-49.

[88] Laine B, Hivet G, Boisse P, Boust F, Lomov SV. Permeability of the woven fabrics: a parametric study. In: Procedings of the 8th ESAFORM conference on material forming, Cluj-Napoca, 2005. p. $995-8$

[89] Robitaille F, Clayton BR, Long AC, Souter BJ, Rudd CD. Geometric modelling of industrial preforms: woven and braided textiles. Proc Inst Mech Eng 1999;213 Part L:69-81.
[90] Robitaille F, Clayton BR, Long AC, Souter BJ, Rudd CD. Geometric modelling of industrial preforms: warp-knitted textiles. Proc Inst Mech Eng 1999;214 Part L:71-90.

[91] Robitaille F, Long AC, Jones IA, Rudd CD. Automatically generated geometric descriptions of textile and composite unit cells. Composites, Part A 2003;34(4):303-12.

[92] Robitaille F, Long A, Sherburn M, Wong CC, Rudd C. Predictive modelling of processing and performance properties of textile composite unit cells: current status and perspectives. In: Proceedings ECCM-11, CD ed., 2004.

[93] Potluri P, Perez Ciurezu DA, Ramgulam RB. Measurement of meso-scale shear deformations for modelling textile composites. Composites, Part A 2006;37(6):303-14.

[94] Carvelli V, Lomov S, Poggi C, Prodromou A, Verpoest I. Analytical and finite element models for the prediction of the mechanical properties of textile composites. In: Proceeding of the 15th AIMETA congress of theoretical and applied mechanics. Taormina (Italy): CD-ROM; 2001.

[95] Zako M, Kurashiki T, Kubo F, Imura M. A multi-scale analysis for structural design of fibrous composites - M3 method. In: 15th international conference on composite materials (ICCM-15), CD ed., Durban, 2005.

[96] Lomov SV, Verpoest I, Bernal E, Boust F, Carvelli V, Delerue J-F, et al. Virtual textile composites software Wisetex: integration with micro-mechanical, permeability and structural analysis. In: Proceedings of the 15 th international conference on composite materials (ICCM-15), CD ed., Durban, 2005.

[97] Kurashiki T, Hirosawa S, Zako M, Lomov SV, Verpoest I. On a numerical simulation of the mechanical behaviour for laminated woven fabric composites under tensile loading. In: Proceedings of the 7th international conference on textile composites (TexComp-7), (Textile 13)1-4, Yonezawa, 2004.

[98] Kurashiki T, Zako M, Hirosawa S, Lomov SV, Verpoest I. Estimation of a mechanical characterization for woven fabric composites by FEM based on damage mechanics. In: Proceedings ECCM-11, CD ed., Rodos, 2004.

[99] Lomov SV, Huysmans G, Luo Y, Parnas R, Prodromou A, Verpoest I, et al. Textile composites: modelling strategies. Composites, Part A 2001;32(10):1379-94.

[100] Ivanov DS, Lomov SV, Verpoest I, Tashkinov AA. Local elastic properties of a shaped textile composite: homogenisation algorithm. In: Proceedings of the 6th ESAFORM conference on material forming, Salerno, 2003. p. 839-42.

[101] Zako M, Tsujikami T, Tsumura T. Development of finite element method considered an anisotropic damaged state for composite materials. In: The 37th Japan congress on materials research. Kyoto (Japan): Society of Materials Science; 1994. p. 174-9.

[102] Zako M, Tsujikami T. On a personal computer program of three dimensional FEM for composites. In: The 36th Japan congress on materials research. Kyoto (Japan): Society of Materials Science; 1993. p. 199-204.

[103] Zako M, Tsujikami T, Takano N, Tsumura T. Development of three-dimensional finite element method for composite materials based on damage mechanics. In: The 38th Japan congress on materials research, 1995. p. 157-62.

[104] Lomov SV, Gusakov AV, Huysmans G, Prodromou A, Verpoest I. Textile geometry preprocessor for meso-mechanical models of woven composites. Compos Sci Technol 2000;60:2083-95.

[105] Lomov SV, Huysmans G, Verpoest I. Hierarchy of textile structures and architecture of fabric geometric models. Textile Res J 2001;71(6):534-43.

[106] Lomov SV, Nakai A, Parnas RS, Bandyopadhyay Ghosh S, Verpoest I. Experimental and theoretical characterisation of the geometry of flat two- and three-axial braids. Textile Res J 2002;72(8):706-12.

[107] Summerscales J, Russell PM. Observations on the fibre distribution and fibre strain in a woven fabric reinforcement. Adv Compos Lett 2004;13(3):135-9. 
[108] Lomov SV, Belov EB, Bischoff T, Ghosh SB, Truong Chi T, Verpoest I. Carbon composites based on multiaxial multiply stitched preforms. Part 1: Geometry of the preform. Composites, Part A 2002;33(9):1171-83.

[109] Loendersloot R, Lomov SV, Akkerman R, Verpoest I. Carbon composites based on multiaxial multiply stitched preforms. Part 5: Geometry of sheared biaxial fabrics. Composites, Part A 2006;37:103-13.

[110] Ruopp A. Geometrical characterisation of structural stitching in carbon composite preforms. Institute of Aircraft Construction, Faculty of Aerospace Engineering and Geodesy. Stuttgart: University of Stuttgart; 2005.

[111] Hess Y, Roth YC, Himmel N. Elastic constants estimation of stitched NCF CFRP laminates based on a finite element unit-cell model. Compos Sci Technol, in press.

[112] Lomov SV, Verpoest I, Peeters T, Roose D, Zako M. Nesting in textile laminates: geometrical modelling of the laminate. Compos Sci Technol 2002;63(7):993-1007.

[113] Crookston JJ, Sherburn MN, Zhao LG, Ooi J, Long AC, Jones IA. Finite element analysis of textile composite unit cells using conventional and novel techniques. In: Proceedings ICCM-15, CD ed., Durban, 2005.

[114] Boisse P, Gasser A, Hivet G. Analyses of fabric tensile behaviour: determination of the biaxial tension-strain surfaces and their use in forming simulations. Composites, Part A 2001;32(10):1395-414.

[115] Chamis CC. Mechanics of composite materials: past, present and future. J Compos Technol Res 1989;11(1):3-14.

[116] Hashin Z. Analysis of properties of fibre reinforced composites with anisotropic constituents. J Appl Mech 1979;46:543-50.

[117] Hashin Z. Analysis of composite materials - a survey. J Appl Mech 1983;50:481-506.

[118] Hashin Z. and Rosen BW. The elastic moduli of fibre reinforced materials. J Appl Mech 1964;31:223-32.

[119] Halpin JC, Tsai SW. Environmental factors in composite materials design. Air Force Materials Laboratory; 1967. p. 67-423.

[120] Kaddour AS, Hinton MJ. The launch of WWFE-II: Benchmarking of $3 \mathrm{D}$ strength and damage theories for polymer fibre composites. In: Proceedings ICCM-15, CD ed., Durban, 2005.

[121] Kaddour AS, Hinton MJ. Tri-axial failure theories for fibre reinforced composites. In: Proceedings ICCM-15, CD ed., 2005.

[122] Rosen BW. Mechanics of composite strengthening. In: Fiber composite materials. Metals Park (OH): ACM; 1964. p. 75.
[123] Hirai T, Yoshida H. The effect of moulding on the mechanical properties of FRP. J Soc Mater Sci Jpn 1974;23:254.

[124] Bakhvalov N, Panasenko G. Homogenization: averaging processes in periodic media. Dordrecht: Kluwer Academic Publishers; 1989.

[125] Pobedrya BE. Mechanics of composite materials. Moscow University; 1984.

[126] Camanho PP, Davila CG, Pinho T, Iannucci L, Robinson P. Prediction of in situ strengths and matrix cracking in composites under transverse tension and in-plane shear. Composites, Part A 2006;37(6):165-76.

[127] Gao F, Boniface L, Ogin SL, Smith PA, GRP. Damage accumulation in woven-fabric CFRP laminates under tensile loading: 2. Modelling the effect of damage on macro-mechanical properties. Compos Sci Technol 1999;59(1):137-45.

[128] Hamelin P, Bigaud D. A numerical procedure for elasticity and failure behaviour prediction of textile-reinforced composite materials. Thermoplast Compos Mater 1999;12(May):201-13.

[129] Hinton MJ, editor. Failure criteria in fibre reinforced polymer composites. The world-wide failure exercise. Amsterdam: Elsevier; 2004.

[130] Zako M, Takano N, Tsujikami T, Uetsuji Y. A proposition for fracture behaviour analysis of composites. In: Proceedings of the 38th Japan congress on materials research, 1995. p. 163-9.

[131] Zako M, Takano N, Tsumura T. Numerical prediction of strength of notched UD laminates by analysing the propagation of intra- and inter-laminar damage. Mater Sci Res Int 1996;2(2):117-22.

[132] Hoffman O. The brittle strength of orthotropic material. J Compos Mater 1967;1(2):200-2006.

[133] Murakami S. Mechanical modeling of material damage. J Appl Mech 1988;55:280.

[134] Cordebois JP, Sidoroff F. Damage induced elastic anisotropy. In: Mechanical behaviour of anisotropic solids. Martinus-Nijhoff; 1982.. p. 761.

[135] Geers MGD, de Borst R, Breckelmans WAM, Peerlings RHJ. Validation and internal length scale determination for a gradient damage model: application to short glass fibre reinforced polypropylene. Int J Solids Struct 1999;36:2557-83.

[136] Geers MGD, de Borst R, Peijs T. Mixed numerical-experimental identification of non-local characteristics of random-fibre-reinforced composites. Compos Sci Technol 1999;59:1569-78. 